Universidad de Lima

Facultad de Ingeniería y Arquitectura

Carrera de Ingeniería Industrial

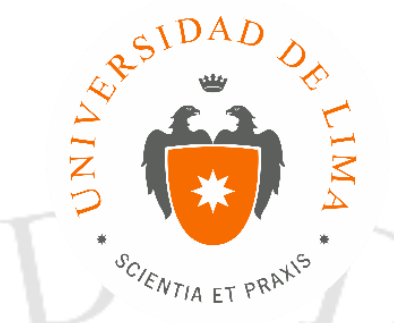

\title{
ESTUDIO DE DIAGNÓSTICO PARA LA MEJORA INTEGRAL DE LA EMPRESA INDUSTRIA CARROCERA QUISPE S.A.C.
}

Trabajo de investigación para optar el grado académico de bachiller en Ingeniería Industrial

\section{Christian Victor Quispe Accostupa}

Código 20143149

\author{
Asesor \\ Fernando Kleeberg Hidalgo
}

Lima - Perú

Enero de 2019 


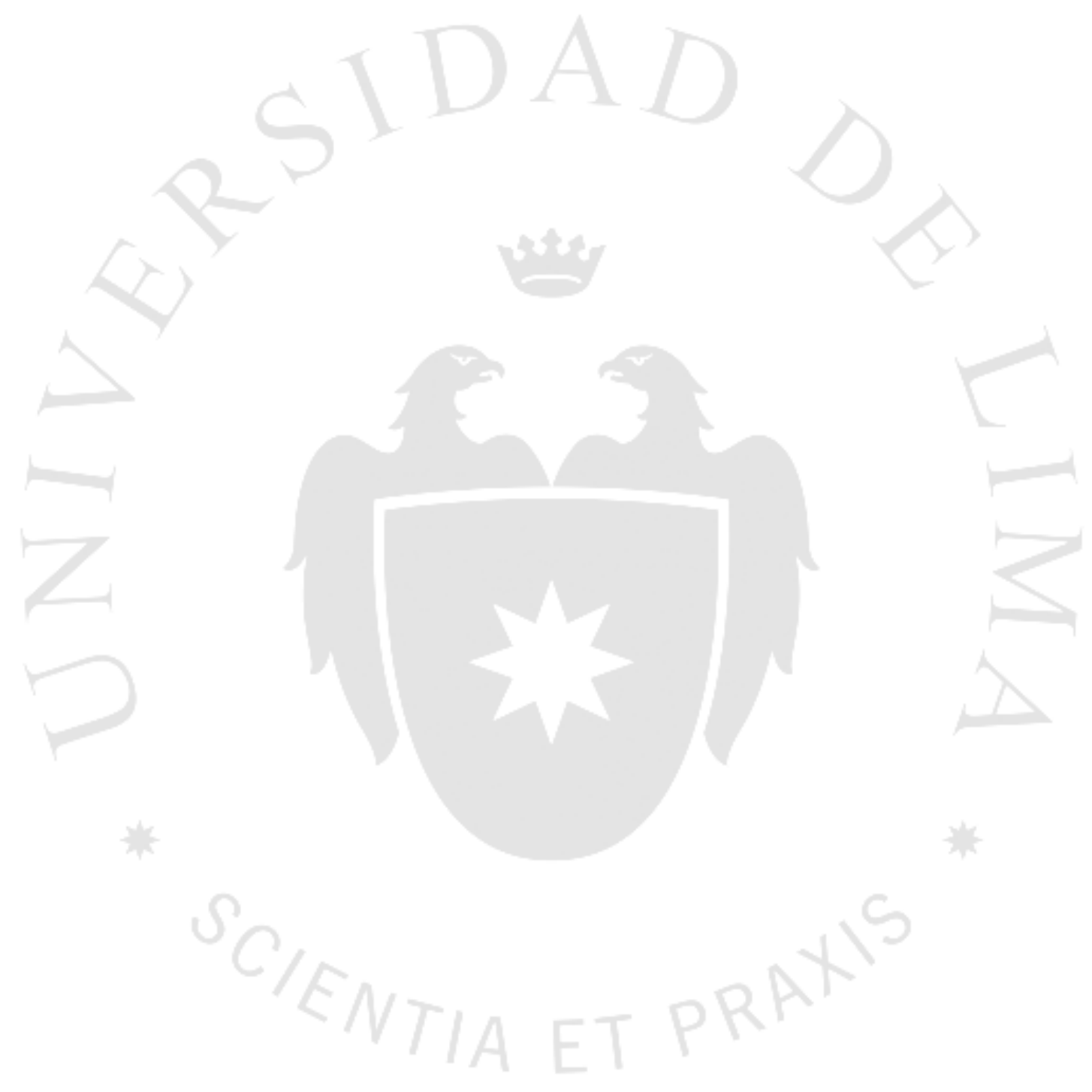


ESTUDIO DE DIAGNÓSTICO PARA LA MEJORA INTEGRAL DE LA EMPRESA INDUSTRIA CARROCERA QUISPE S.A.C.

\section{TABLA DE CONTENIDO}


RESUMEN EJECUTIVO. 9

CAPÍTULO I: CONSIDERACIONES GENERALES DE LA INVESTIGACIÓN. . .10

1.1 Antecedentes de la empresa .................................................... 10

1.1.1 Breve descripción de la empresa..............................................10

1.1.2 Descripción de los servicios ofrecidos........................................10

1.1.3 Descripción del mercado objetivo de la empresa ........................12

1.1.4 Descripción de la problemática actual de la empresa ..................12

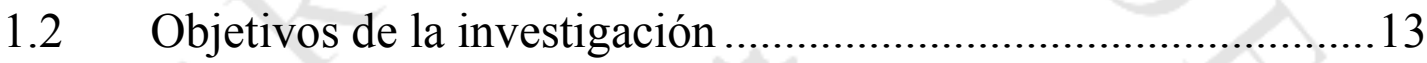

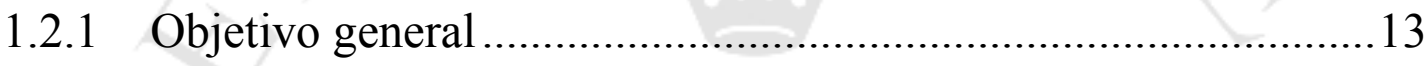

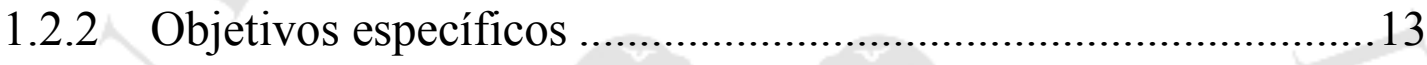

1.3 Alcance y limitaciones de la investigación..................................13

$1.4 \quad$ Justificación de la investigación ................................................. 14

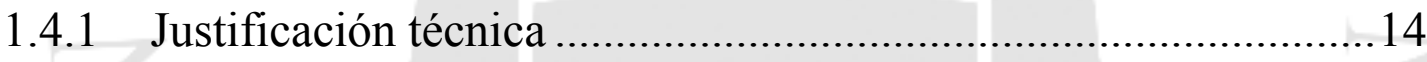

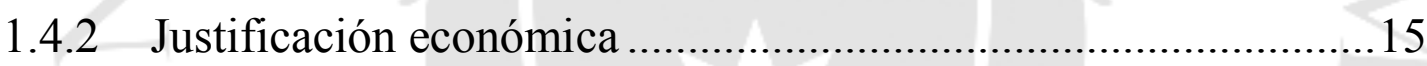

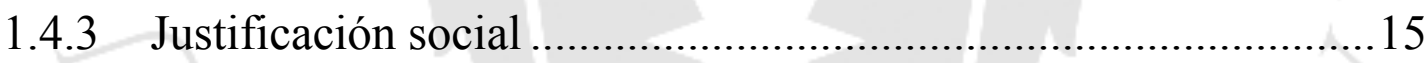

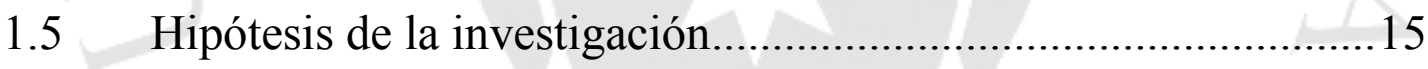

1.6 Marco referencial de la investigación .........................................16

1.7 Marco conceptual de la investigación ..........................................17

CAPÍTULO II: ANÁLISIS EXTERNO DE LA EMPRESA....18

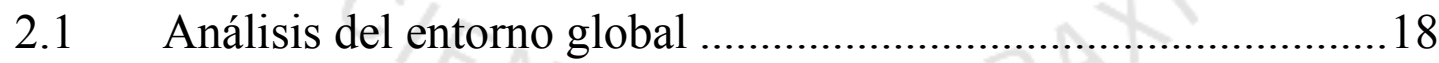

2.2 Análisis del entorno competitivo ...............................................24

2.3 Identificación y evaluación de las oportunidades y amenazas del entorno. 26

CAPÍTULO III. DIAGNÓSTICO DEL PROCESO ESTRATÉGICO 32

3.1 Análisis del Proceso Estratégico 32 
3.1.1 Análisis del direccionamiento estratégico: visión, misión y objetivos organizacionales 32

3.1.2 Análisis de la estrategia general de la empresa............................32

3.1.3 Análisis de la estructura organizacional de la empresa ...............33

CAPÍTULO IV. DIAGNÓSTICO DEL PROCESO COMERCIAL36

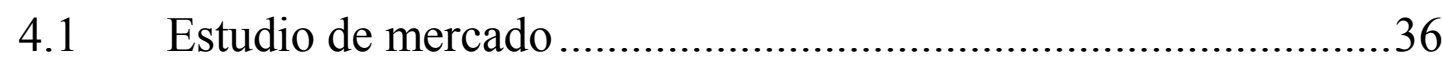

4.1.1 Descripción del cliente y consumidor ...........................................36

4.1.2 Descripción comercial de productos o servicios............................36

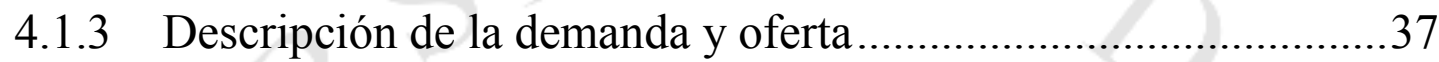

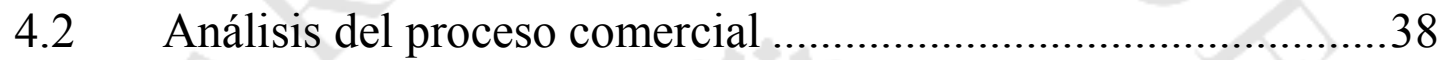

4.2.1 Análisis de resultados comerciales ...........................................38

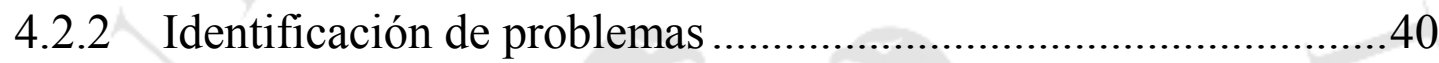

4.2.3 Determinación de fortalezas y debilidades ..................................43

CAPÍTULO V. DIAGNÓSTICO DEL PROCESO OPERATIVA

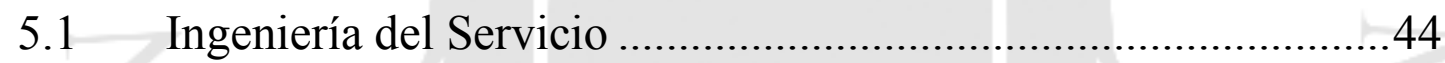

5.1.1 Descripción técnica de los productos o servicios .........................44

5.1.2 Descripción de las materias primas...............................................46

5.1.3 Identificación de los principales proveedores.............................47

5.2 Análisis del proceso operativo ..................................................48

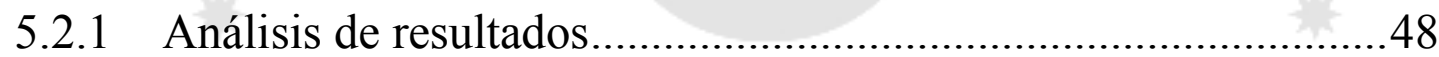

5.2.2 Identificación de problemas y causa raíz ...................................53

5.2.3 Determinación de fortalezas y debilidades .................................55

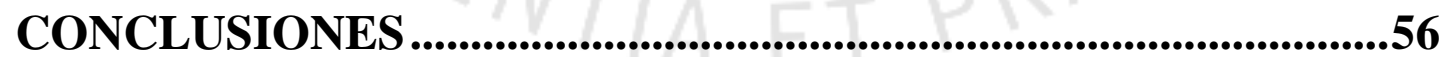

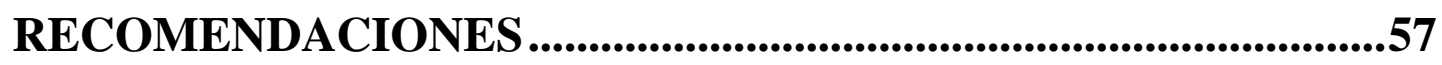

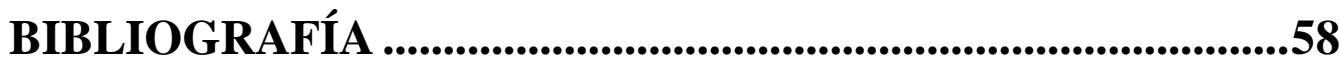

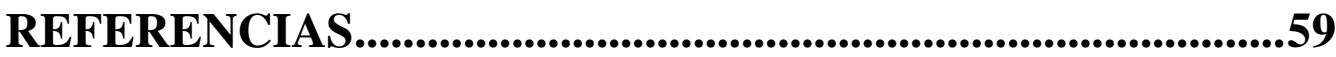




\section{ÍNDICE DE TABLAS}

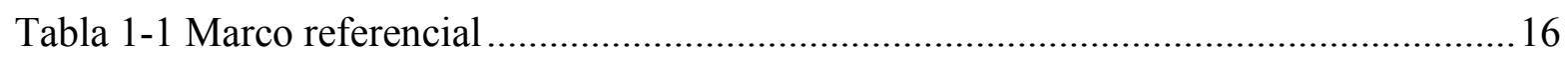

Tabla 4-1 Detalle tipo de vehículo vendido hasta abril del 2018 ....................................... 40

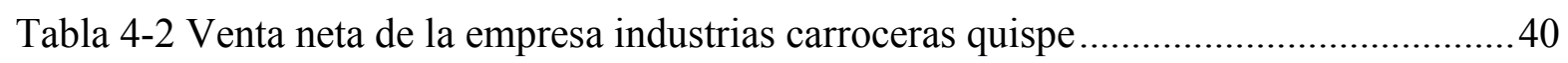

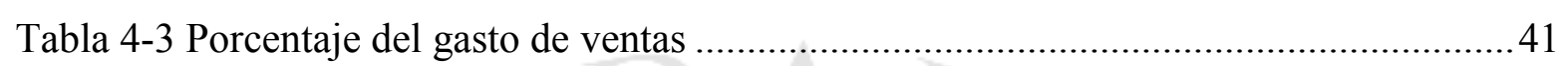

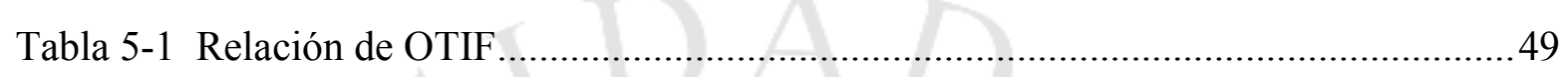

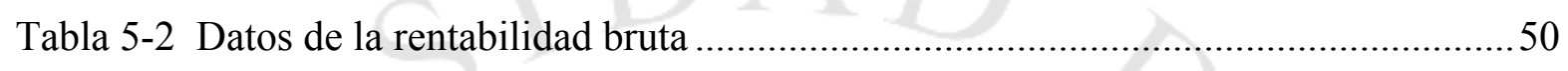

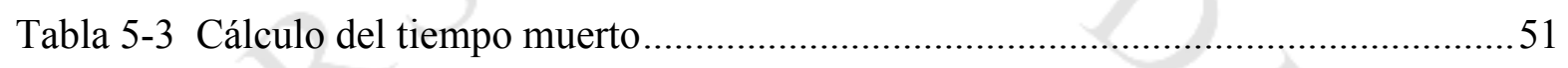

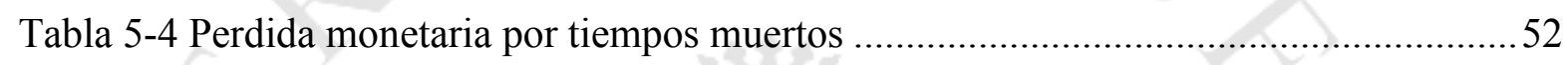




\section{ÍNDICE DE FIGURAS}

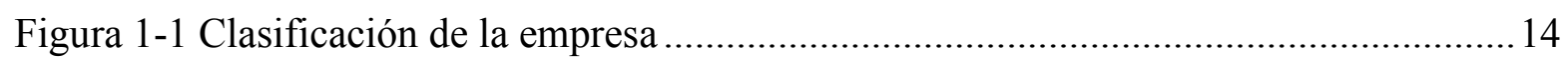

Figura 2-1 Producto Bruto Interno del 2008_I - 2017_II ................................................ 18

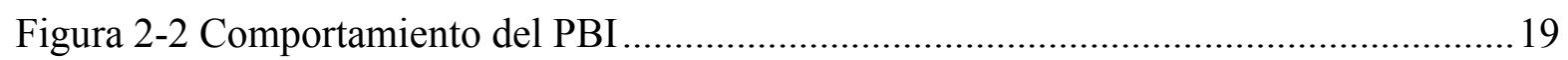

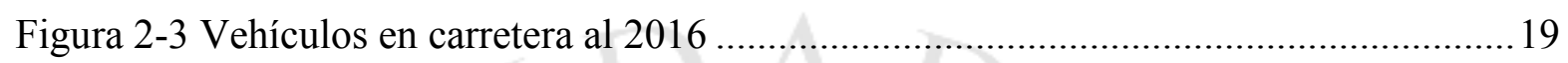

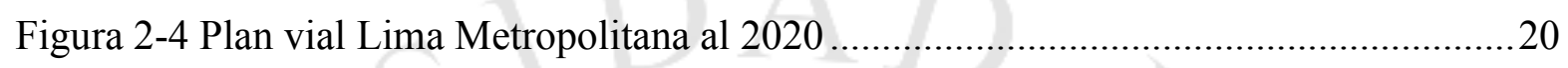

Figura 2-5 Venta de vehículos livianos y pesados en Latinoamérica ...................................20

Figura 2-6 Distribución modal \% en Lima y Callao ............................................................ 21

Figura 2-7 Distribución de los tipos de viajes en Lima y Callao .........................................22

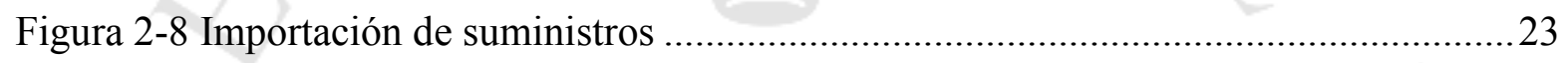

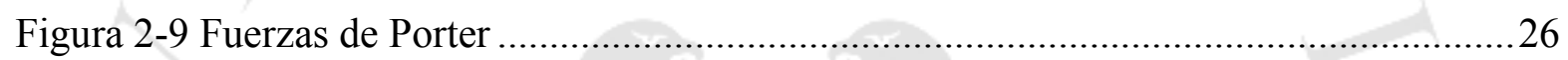

Figura 2-10 Asientos reclinables de ómnibus interprovincial..............................................27

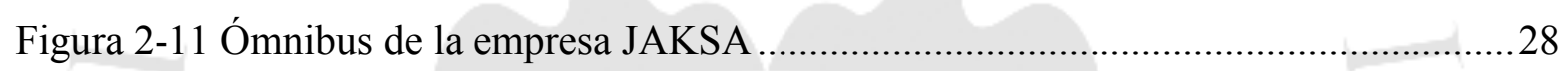

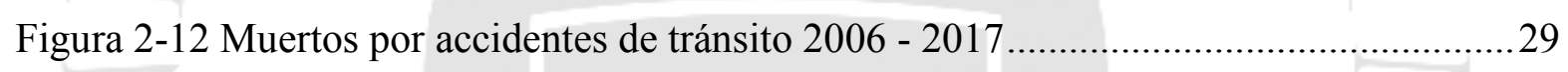

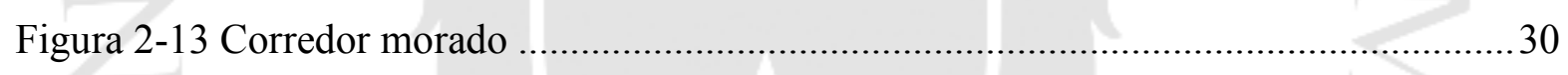

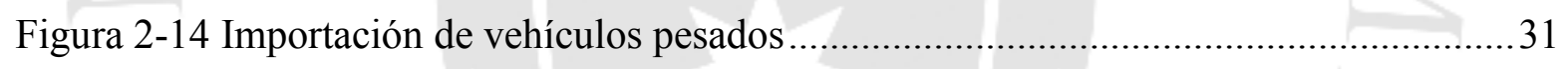

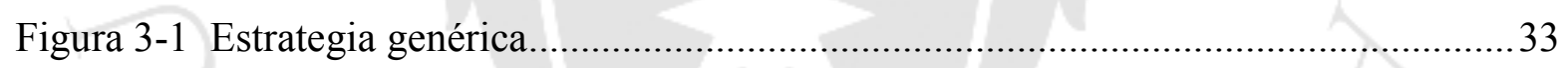

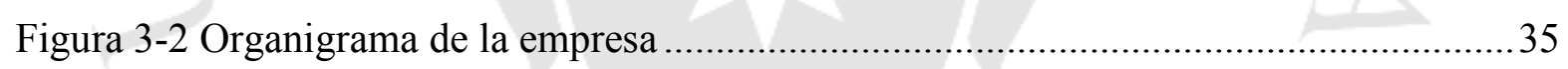

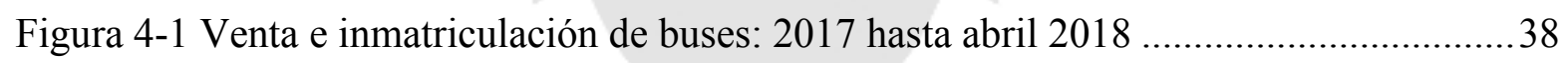

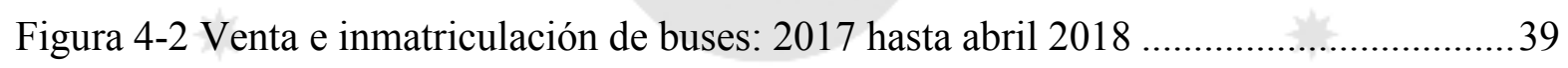

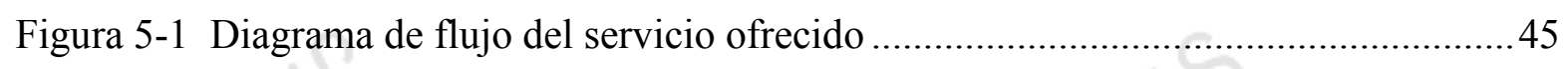

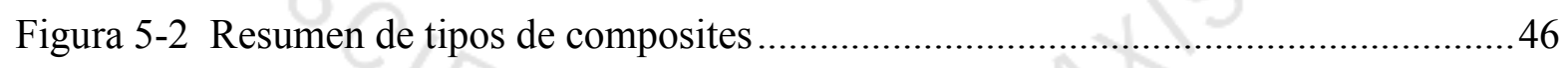

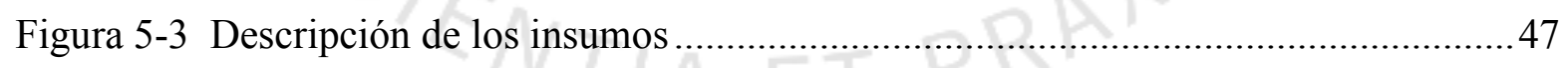

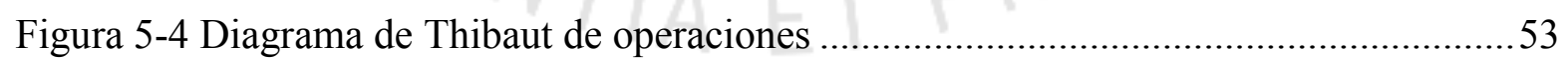

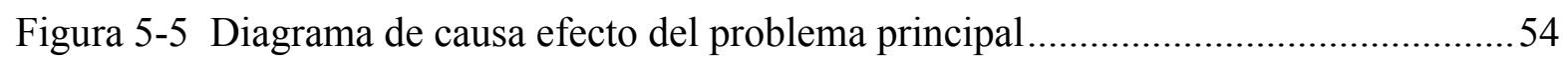




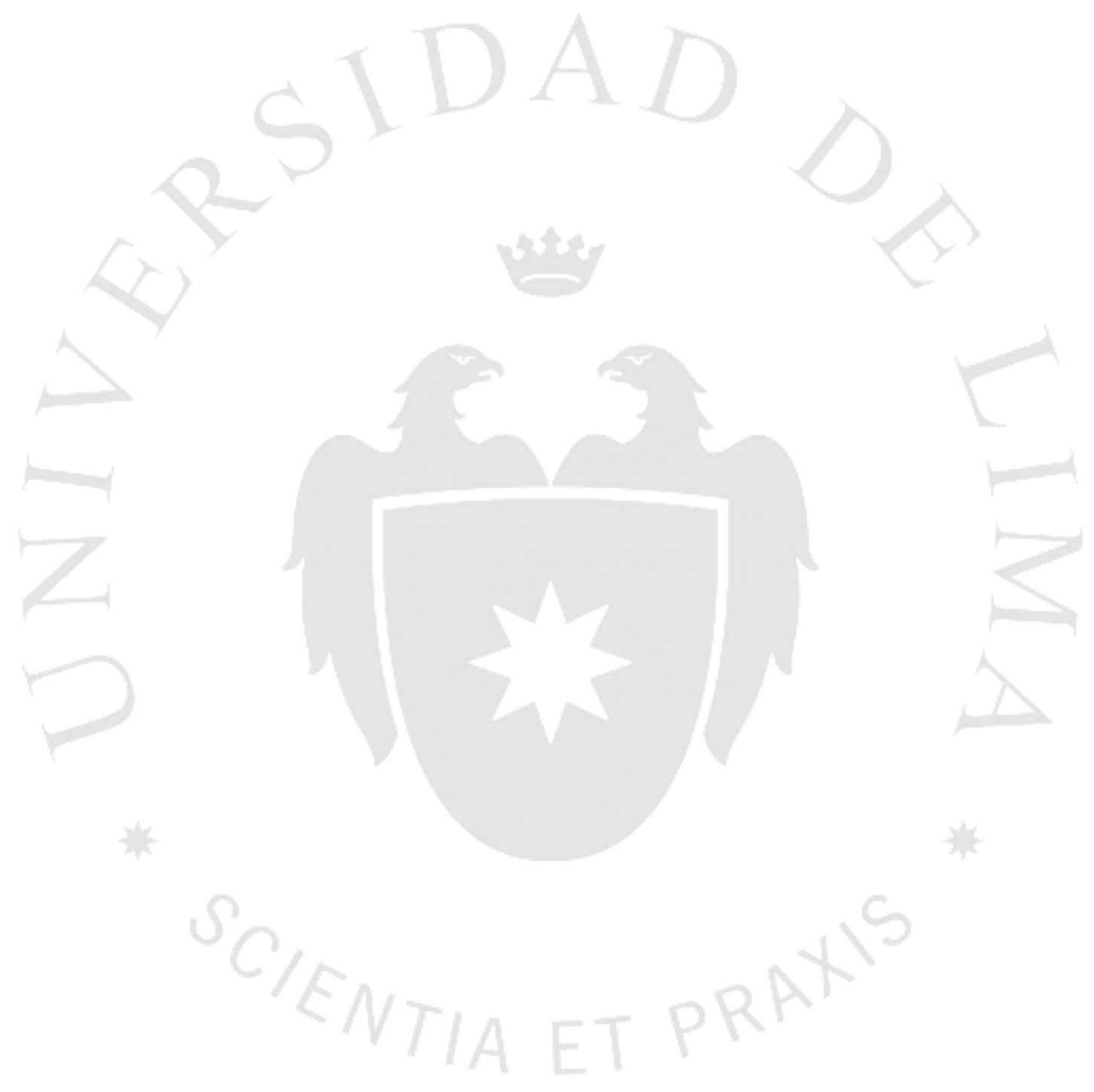




\section{Resumen ejecutivo}

El presente proyecto de investigación consiste en el diagnóstico de los principales problemas que mantiene la empresa Industria Carrocera Quispe S.A.C., para lo cual, se espera realizar el planteamiento de las propuestas de solución, que apoyen a la eliminación y reducción de estos problemas.

En el primer capítulo, se realizó una exhaustiva recolección de datos que se relaciona con la empresa, como son sus inicios, el desarrollo de esta en el mercado, etc. Además, se realiza el planteamiento del objetivo general, los específicos y la hipótesis del presente trabajo, el cual, en el final del proyecto se podrá responder con sustento ingenieril.

En el segundo capítulo, se analizó el entorno de la empresa, mediante las fuerzas de Porter y el análisis PEST. En el cual, se pudo determinar que la fuerza de amenaza de nuevos entrantes, la rivalidad entre competidores y la negociación con los clientes son altas, además, la fuerza de negociación con los proveedores y la amenaza de productos sustitutos resultaron bajas.

En el tercer capítulo, se encontró que la empresa presenta una estrategia genérica de segmentación por costos dado que, no abarca todo el parque automotriz y solo se enfoca en el rubro de la reparación de buses siniestrados.

Finalmente, se realiza el diagnóstico de las distintas áreas que maneja la empresa, como son el área comercial, de procesos estratégicos y operativos. Con lo cual, se halló que los problemas que presenta la empresa en el área comercial son la falta de una política eficiente de promoción y distribución. Además, en el área de operaciones se registró que el porcentaje de tiempo muerto de los distintos trabajadores es de $7.81 \%$ lo cual, conlleva a una pérdida anual que asciende a $\mathrm{S} /$. 42,195.00 soles. 


\section{Capítulo I: Consideraciones generales de la investigación}

\subsection{Antecedentes de la empresa}

\subsubsection{Breve descripción de la empresa}

Industria Carrocera Quispe S.A.C. es una empresa fundada el 18 de diciembre del 2008 por el señor Victor Quispe Huillca y su esposa, la señora Alejandrina Accostupa Uñapillco. La empresa cuenta con 22 operarios que realizan las actividades necesarias dentro de las distintas áreas que poseen para satisfacer las necesidades de sus clientes. La empresa realiza todas sus operaciones en un local alquilado en el distrito de Ate- Vitarte. Además, la empresa cuenta con un crecimiento sostenido desde su creación, debido a la calidad de sus servicios ofrecidos.

La empresa en mención es de servicios cuyo rubro está enfocado en la fabricación y reparación de buses interprovinciales y urbanos. Además, realiza servicios de pintado, planchado o instalación de algún implemento en el bus dependiendo de las necesidades de los clientes.

La empresa adquirió un terreno en el distrito de San Juan de Lurigancho, donde proyectan ampliar el mercado que tienen hasta el momento, dado que, el lugar donde se encuentran sus instalaciones actuales, es de carácter en alquiler; y es por esto, que para el año 2019 se trasladaran todas las operaciones al nuevo taller. Además, la nueva ubicación es beneficiosa dado que, muchos de los clientes de la empresa se encuentran operando en ese distrito.

\subsubsection{Descripción de los servicios ofrecidos}

Los servicios que ofrece la empresa-Industria Carrocera Quispe SAC son de reparación de buses siniestrados, fabricación de carrocerías para buses nuevos o pintura general de buses nuevos, semi nuevos o deteriorados.

\section{- El servicio de reparación de buses siniestrados}

Generalmente, es ofrecido a los clientes que cuentan con buses asegurados; es decir, el dueño del vehículo se encuentra afiliado a una compañía de seguros que cubre 
cualquier accidente que pueda tener el bus mientras este está desempeñando sus labores o de acuerdo al convenio que haya estipulado el asegurado en los términos del contrato

El primer paso que se realiza cuando llega un bus siniestrado es comunicarle a la compañía de seguros que dicha unidad se encuentra en el taller de reparación, para que dispongan de un técnico que se encargará de revisar los daños en la unidad. Después, se procede a elaborar el presupuesto que será evaluado por un "bróker", persona la cual se encarga de realizar el reajuste de los precios del presupuesto.

Luego de los trámites administrativos, los operarios se encargan de refaccionar el problema que haya tenido el cliente; por ejemplo, si el bus fue siniestrado por el impacto contra un poste los operarios se encargarán de refaccionar la parte delantera del vehículo. Este proceso de reparación tarda entre 10 y 25 días hábiles dependiendo de la gravedad del siniestro, luego de esto, terminada la operación de refaccionado, el vehículo se traslada hacia el área de pintado.

\section{- La operación de pintado}

Esta se realiza solo sobre todo el bus y, como un sello de cortesía propio de la empresa, este pintado es ofrecido al cliente a todo el vehículo en general dado que generalmente, en los talleres de reparación de unidades siniestradas, solo se realiza el pintado del paño afectado.

En ocasiones también llegan al taller clientes que desean renovar sus vehículos por algún motivo en especial, sea este cambio de empresa de transportes, remodelación por temas de estética, entre otros. Para estos casos, la empresa también brinda los servicios independientes de pintura y remodelación con fibra de vidrio.

Una vez terminado el servicio ofrecido, el cliente firma una constancia que certifica que su unidad se encuentra en perfectas condiciones, es decir, se reparó el problema y no se vio afectada la funcionalidad de este en general. Finalmente, se realiza la factura al nombre de la compañía de seguros, o del cliente independiente sea cual sea el caso, y desde ese momento, se espera 30 días hábiles para que la empresa pueda cobrar. 


\subsubsection{Descripción del mercado objetivo de la empresa}

El servicio de reparación de buses siniestrados, generalmente, es ofrecido a los clientes que cuentan con buses asegurados. Es decir, el propietario de dicho bus se encuentra afiliado a una compañía de seguros que cubre cualquier accidente que pueda tener el bus mientras estuvo realizando sus labores.

También, la fabricación de carrocerías nuevas o el pintado de los vehículos se ofrecen a clientes que tengan unidades de transporte interprovincial o para buses de tamaño medio o grande, generalmente estos pueden llegar a ser también clientes que tienen buses o combis que realizan transporte público en las rutas de Lima metropolitana.

Geográficamente hablando, “... el mercado objetivo al cual se encuentra dirigido la empresa Industria Carrocera Quispe S.A.C. es Lima Metropolitana; sin embargo, la empresa cuenta con clientes que provienen del norte, centro y sur del país. Esto se da, gracias a que, el dueño y gerente se ha creado una buena imagen ante sus clientes y estos mismos lo recomiendan ante sus amigos." (Quispe Accostupa, Contreras Huatuco, \& Bravo Lando, 2017).

Según Quispe \& Contreras, es así como la red de clientes de la empresa Industria Carrocera Quispe SAC se ha ampliado en pocos años de creación. La empresa concentra la mayor parte de sus clientes en el distrito de San Juan de Lurigancho, debido a que, cuenta con una alianza estratégica con la empresa que provee de unidades al Corredor Morado.

\subsubsection{Descripción de la problemática actual de la empresa}

En la actualidad, el parque automotor de los ómnibus ha estado en aumento, dado que índice demográfico, también estuvo en crecimiento. Esta es una razón, por la cual, analizar las diferentes características que debe poseer un taller que realice mantenimiento a estas unidades es valiosísima.

El tema de investigación en el cual nos enfocaremos, será sobre una mejora integral de la empresa Industria Carrocera Quispe S.A.C., dado que, al ser una empresa constituida sin apoyo profesional, presenta varias oportunidades de mejora en las distintas áreas que manejan. 
Nos enfocaremos en la mejora de la gestión de la calidad y la seguridad y salud ocupacional de sus trabajadores; para esto, desplegaremos los conocimientos adquiridos en las distintas materias que realizamos en nuestra vida universitaria.

Y con la esperanza, de que al final de la investigación poder responder la pregunta de si: ¿Es viable técnica y económica de la implementación de una mejora que permita optimizar los procesos críticos que ayuden a aumentar la rentabilidad de la empresa Industria Carrocera Quispe SAC?

\subsection{Objetivos de la investigación}

\subsubsection{Objetivo general}

- Realizar el diagnóstico de los procesos críticos que maneja de la empresa Industria Carrocera Quispe S.A.C. para plantear una propuesta de solución.

\subsubsection{Objetivos específicos}

- Identificar los procesos críticos de la empresa Industria Carrocera Quispe S.A.C. tanto en las áreas de producción como en las áreas administrativas, así como evaluar los indicadores de desempeño de estos procesos como productividad e indicadores financieros durante el primer año de diagnóstico.

- Determinar las oportunidades y amenazas de la empresa Industria Carrocera Quispe S.A.C. realizando el análisis de las fuerzas de porter y del entorno global de la empresa.

- Realizar un diagnóstico preliminar integral de la empresa Industria Carrocera Quispe S.A.C; es decir, a partir de los indicadores cuantificados y evaluados en los procesos críticos de la empresa, evaluar la interrelación de estos y definir los principales problemas para la mayor cantidad de fallas en los KPI metas; todo durante el primer año de diagnóstico.

\subsection{Alcance y limitaciones de la investigación}

La unidad de análisis del alcance del proyecto de investigación está dirigido a los propietarios de buses interprovinciales y urbanos, es decir, son los clientes que suelen reparar o dar mantenimiento a sus unidades en la empresa Industria Carrocera Quispe S.A.C. 
Figura 1-1

Clasificación de la empresa

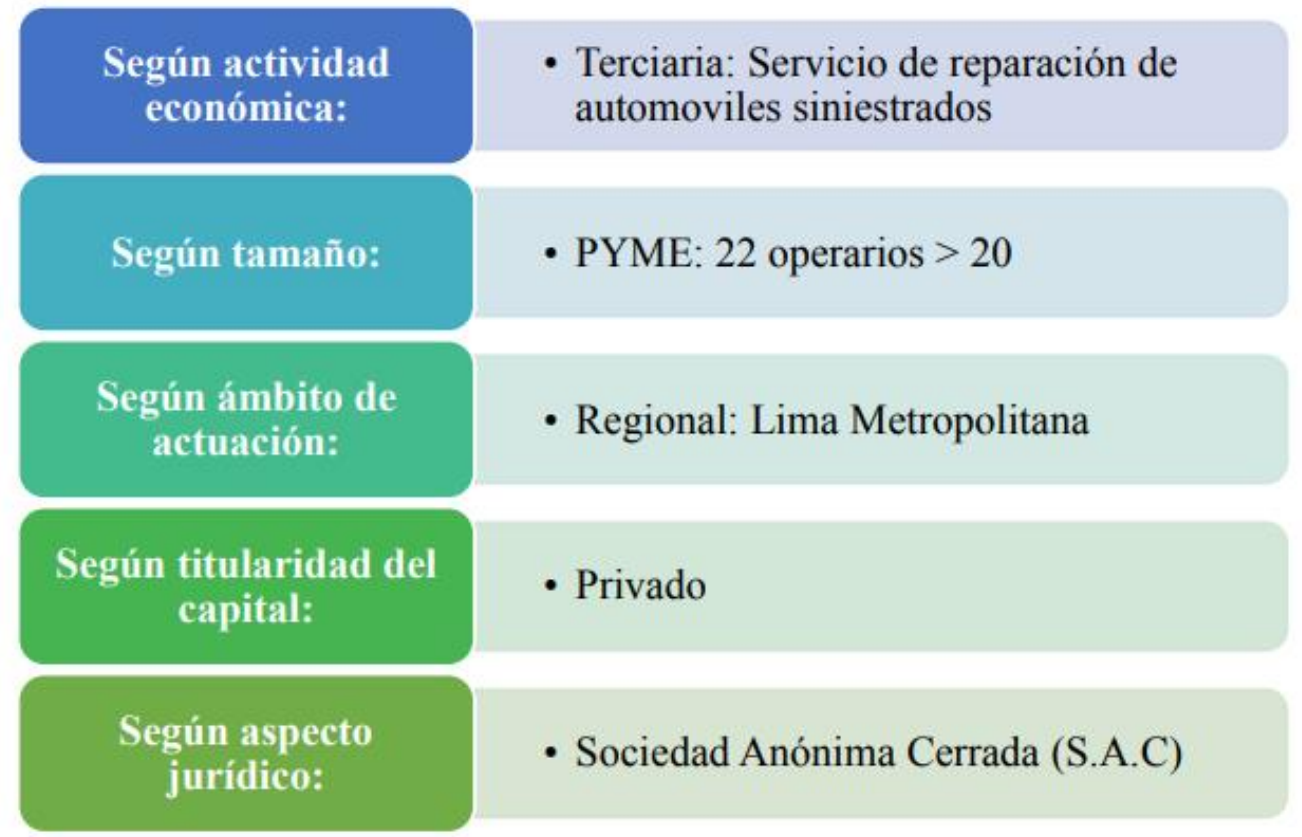

Elaborado por Quispe \& Contreras (2017)

El área geográfica del proyecto es Lima Metropolitana, debido a que, los clientes de esta empresa están ubicados en esta ciudad.

En cuanto a las limitaciones de la investigación encontramos el control presupuestal de la empresa como el principal limitador para el desarrollo de políticas de mejora. Otra limitación se encuentra al momento de conseguir información del mercado y del sector de reparaciones automotrices, al ser un mercado de difícil acceso y con bajo flujo de información.

\subsection{Justificación de la investigación}

\subsubsection{Justificación técnica}

En términos técnicos la realización de una mejora integral en una empresa está delimitada por el uso se la tecnología que se utilizará y de las metodologías existentes. Debido a esto, mediante el uso de metodologías como las 5S, o de redistribución de planta se puede adoptar conceptos de mejora integrales que permitirán optimizar las operaciones de la empresa.

Es también importante mencionar que, dado el diagnóstico preliminar hecho a la empresa, nos encontramos en la necesidad de implementar sistemas de 
monitoreo de materiales y/o contables, ERP's que se encuentran en el mercado son aplicables y factibles de aplicar en el sistema empresarial de "Industrias Carroceras Quispe"; el principal indicador para escoger el ERP a usar será la relación beneficios/precio de cada uno de estos sistemas.

Los beneficios técnicos esperados en esta mejora, como se comentó, corresponden a aspectos operacionales como: mejor distribución de las áreas del taller, mayor limpieza y orden, mejor distribución administrativa, etc.

\subsubsection{Justificación económica}

Los beneficios esperados a alcanzar con la propuesta de mejora corresponden principalmente a mejorar la rentabilidad de la empresa; este aumento también se verá acompañado por unas mejores ratios de liquidez y mayor capacidad de ahorro en distintos rubros.

\subsubsection{Justificación social}

Al ser este proyecto de investigación una propuesta de mejora a una empresa privada el principal beneficio es de índole económico para los dueños de la empresa; sin embargo, también se esperan beneficios en los aspectos sociales, como: beneficios ambientales, al implementar políticas de reciclaje y reuso de materiales; beneficios de desarrollo social, al implementar programas para contratar a vecinos de la zona industrial en donde se establecerá la empresa.

\subsection{Hipótesis de la investigación}

Nuestro trabajo de investigación se basará en la siguiente hipótesis:

Es rentable implementar una mejora que permita optimizar los procesos críticos que ayuden a aumentar la rentabilidad de la empresa Industria Carrocera Quispe S.A.C. 


\subsection{Marco referencial de la investigación}

Tabla 1-1

Marco referencial

\begin{tabular}{|c|c|}
\hline & anzas y Sir \\
\hline $\begin{array}{l}\text { Referencia 1: Mejora } \\
\text { integral de un taller } \\
\text { de servicios del } \\
\text { sector automotriz } \\
\text { Autor: Fernando } \\
\text { Enrique Peralta Vidal } \\
\text { Fecha: } 2012 \\
\text { Repositorio: Alicia }\end{array}$ & $\begin{array}{l}\text { Las similitudes son que al igual que nuestro proyecto de investigación, el } \\
\text { ingeniero Fernando Peralta se enfoca en una mejora integral de una empresa de } \\
\text { servicios del sector automotriz, es decir, un taller donde realizan el mantenimiento } \\
\text { de unidades vehiculares en la ciudad de Lima. Sin embargo, la diferencia radica } \\
\text { en el tipo de unidades que utiliza en su análisis, ya que son los vehículos ligeros o } \\
\text { livianos, los cuales, en la empresa que estamos desarrollando nuestra } \\
\text { investigación, no realizan mantenimiento para esas unidades. Las unidades que } \\
\text { realizan su mantenimiento en la empresa Industria Carrocera Quispe S.A.C. son } \\
\text { los ómnibus interprovincial y de transporte público. }\end{array}$ \\
\hline $\begin{array}{l}\text { Referencia 2: } \\
\text { Aplicación de Lean } \\
\text { Manufacturing en el } \\
\text { proceso de } \\
\text { conversión de hojas } \\
\text { de planta lijas en la } \\
\text { empresa QROMA } \\
\text { S.A. } \\
\text { Autor: Diego Miguel } \\
\text { Meléndez Rodríguez } \\
\text { Fecha: } 2017 \\
\text { Repositorio: Alicia }\end{array}$ & $\begin{array}{l}\text { El beneficio que nos proporciona esta referencia, es tomar conocimiento de cómo } \\
\text { se aplica la metodología de Lean Manufacturing, la cual aportaría de gran manera } \\
\text { en nuestra investigación para mejorar el indicador de la eficiencia. Es decir, al } \\
\text { eliminar los procesos que no son totalmente necesarios, se reduce el costo de } \\
\text { ventas, por lo cual, la productividad aumentará al igual que su rentabilidad neta. } \\
\text { Pero la diferencia con nuestro proyecto es que la empresa que nos encontramos } \\
\text { investigando es de servicios mientras QROMA S.A. es una empresa de } \\
\text { comercialización de productos. }\end{array}$ \\
\hline $\begin{array}{l}\text { Referencia 3: } \\
\text { Mejora del proceso } \\
\text { de compras y ventas } \\
\text { de repuestos en la } \\
\text { empresa laboratorio } \\
\text { diesel Senatinos S.A. } \\
\text { Autor: Maria Elena } \\
\text { Cárdenas Mora } \\
\text { Fecha: } 2015 \\
\text { Repositorio: PUCP }\end{array}$ & $\begin{array}{l}\text { Este trabajo de mejora empresarial ofrece una visión general de un mercado } \\
\text { objetivo cercano al que evaluamos nosotros en nuestro trabajo y, de la misma } \\
\text { forma, busca implementar una propuesta de mejora en un proceso en particular de } \\
\text { la empresa. Es una referencia importante a la hora de abordar temas y puntos } \\
\text { aplicables en el mercado de repuestos automotrices peruano. Sin embargo, el } \\
\text { enfoque que toma el trabajo es sobre la mejora de un proceso de la empresa. }\end{array}$ \\
\hline
\end{tabular}

Fuente Industrias Carroceras Quispe (2018)

Elaboración propia 


\subsection{Marco conceptual de la investigación}

La propuesta de este proyecto va ligada con conceptos de mejora y diagnóstico propuestos por diferentes investigadores y pedagogos, estas metodologías y herramientas de diagnóstico integral permiten evaluar la situación de la empresa y proponer mejoras como implementación de ERP's para mejorar la estructura y flujo de información de la empresa, o implementar metodologías de mejora en temas de orden para el área de producción como las 5'S, algunos de los conceptos que se podrían aplicar y serán el objeto de estudio de este proyecto de investigación se listan a continuación:

\section{- Fuerzas de Porter}

El modelo de las 5 Fuerzas de Porter es “... una herramienta metodológica de planificación estratégicadesarrollada por Michael Porter, profesor de la Universidad de Harvard, en 1979. Según él mismo, la rentabilidad de un mercado o segmento viene determinado por 5 grandes fuerzas. La rentabilidad de una industria viene determinada por la rivalidad con los competidores (1era fuerza) que a su viene dada por otros cuatro elementos o fuerzas: Las amenazas de nuevos competidores (2da fuerza), el poder negociador de los clientes (3era fuerza), la amenaza de nuevos productos o servicios (4ta fuerza) y el poder negociador de los proveedores (5ta fuerza)." (Foda-Dafo, 2018)

\section{- Metodología de las $5 \mathrm{~S}$}

"Es un programa de trabajo para talleres y oficinas que consiste en desarrollar actividades de orden/limpieza y detección de anomalías en el puesto de trabajo,..., mejorando el ambiente de trabajo, la seguridad y la productividad." (Sacristán, 2005)

Es esta la principal herramienta de mejora que evaluaremos para implementar en el área productiva, debido a la sencillez y eficacia que presenta en su metodología.

\section{- Análisis FODA}

Es una herramienta de estudio para la situación de la empresa, esta técnica, también conocida como DAFO por sus siglas en inglés, analiza las fortalezas, debilidades de la empresa y provee las oportunidades y amenazas que la empresa podría acarrearse en un futuro.

\section{- Balance Score Card}

Es una herramienta de diagnóstico que permite enlazar estrategias y objetivos clave con el resultado de la empresa analizándola por las áreas críticas de esta. 


\section{Capítulo II: Análisis externo de la empresa}

\subsection{Análisis del entorno global}

- Entorno económico

Según el Informe de Actualización Macroeconómico Multianual 2018 - 2017 (IAPM) que presentó el Ministerio de Economía y Finanzas se prevé alcanzar un crecimiento de $5 \%$ al 2021. "Este año el PBI acelerará su ritmo de expansión, del 2.5\% logrado el 2017 a 3.6\%, principalmente por el crecimiento de la inversión pública en 17.5\% y un mayor impulso a la inversión privada, que crecería 4.5\%." (MEF, 2018)

En el siguiente cuadro se aprecia el comportamiento del crecimiento del PBI histórico desde el 2008 a inicios del 2017.

\section{Figura 2-1}

Producto Bruto Interno del 2008_I - 2017_II

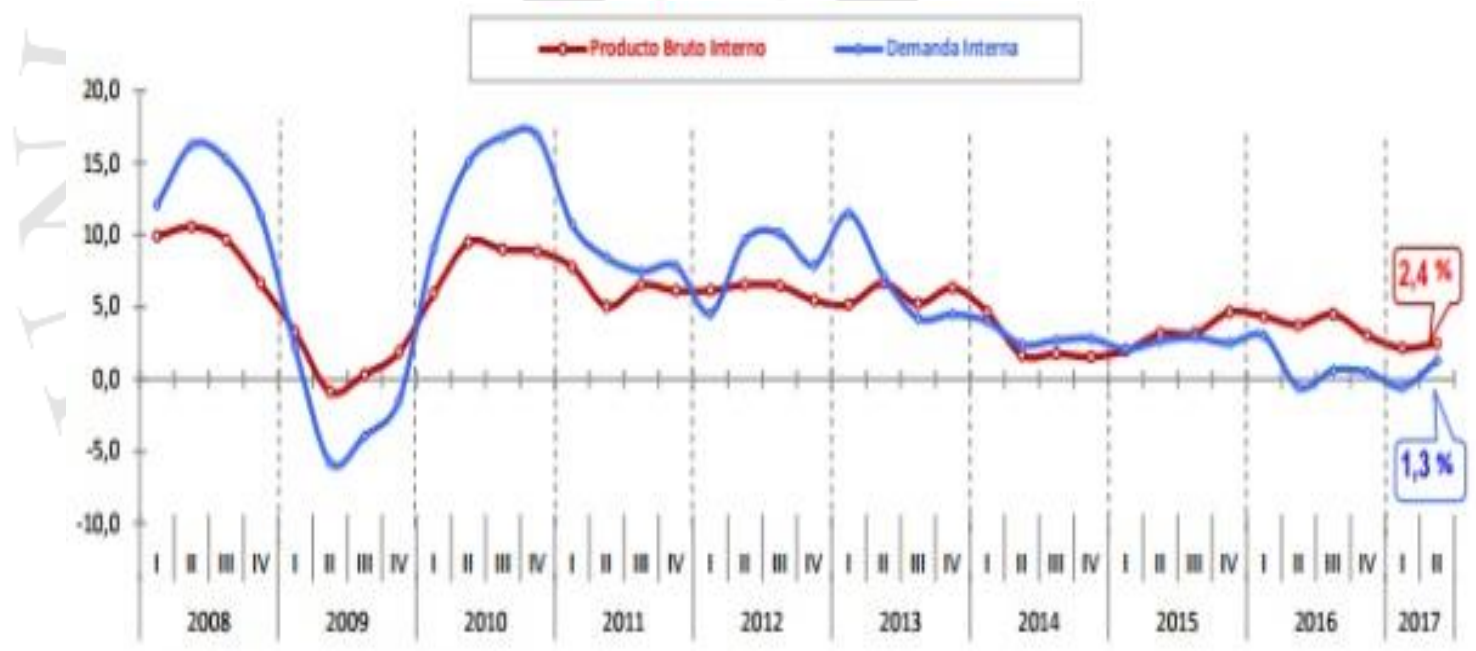

Fuente: Instituto Nacional de Estadística e Informática (2017)

Elaboración propia

Adjuntamos también un cuadro con las proyecciones del crecimiento del PBI elaborado por el Ministerio de Economía y Finanzas en el 2016 para los próximos 5 años. 


\section{Figura 2-2}

Comportamiento del PBI

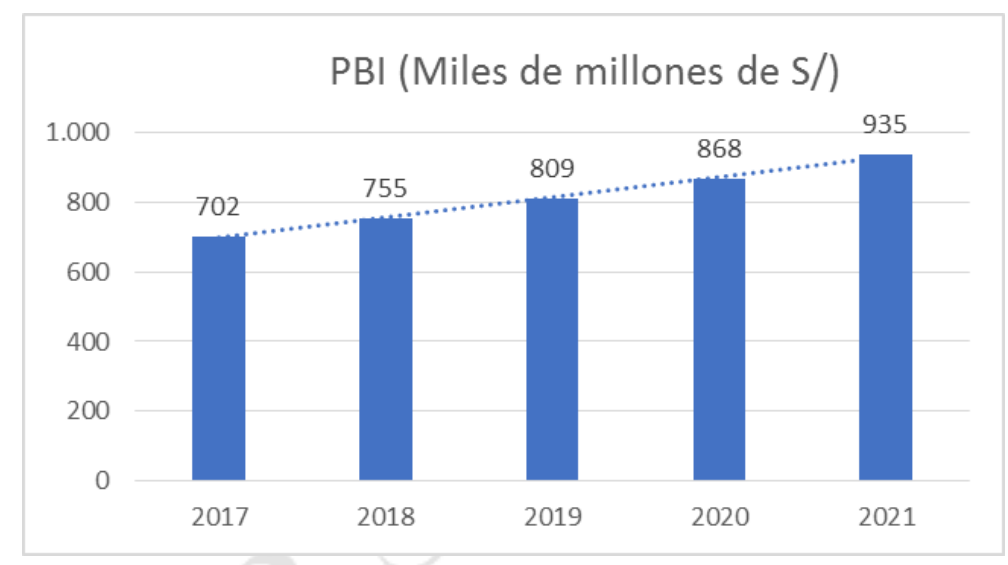

Fuente: MEF (2017)

Elaboración Propia

Como se observa, se espera una continua alza en los siguientes años para el desarrollo económico en términos general. De la misma forma, el parque automotor y especialmente el desarrollo económico en Lima esperan un crecimiento económico y particularmente un aumento en la cantidad de inversión del transporte público en la región metropolitana, así “... en el periodo 2016-2017 se incrementó en más de dos veces la flota vehicular autorizada para el transporte terrestre de personas". Como lo expresan las cifras proporcionadas por el Ministerio de Transportes y Comunicaciones en colaboración con la Asociación Automotriz del Perú, este incremento también se ve reflejado en el aumento del gasto público.

\section{Figura 2-3}

Vehículos en carretera al 2016

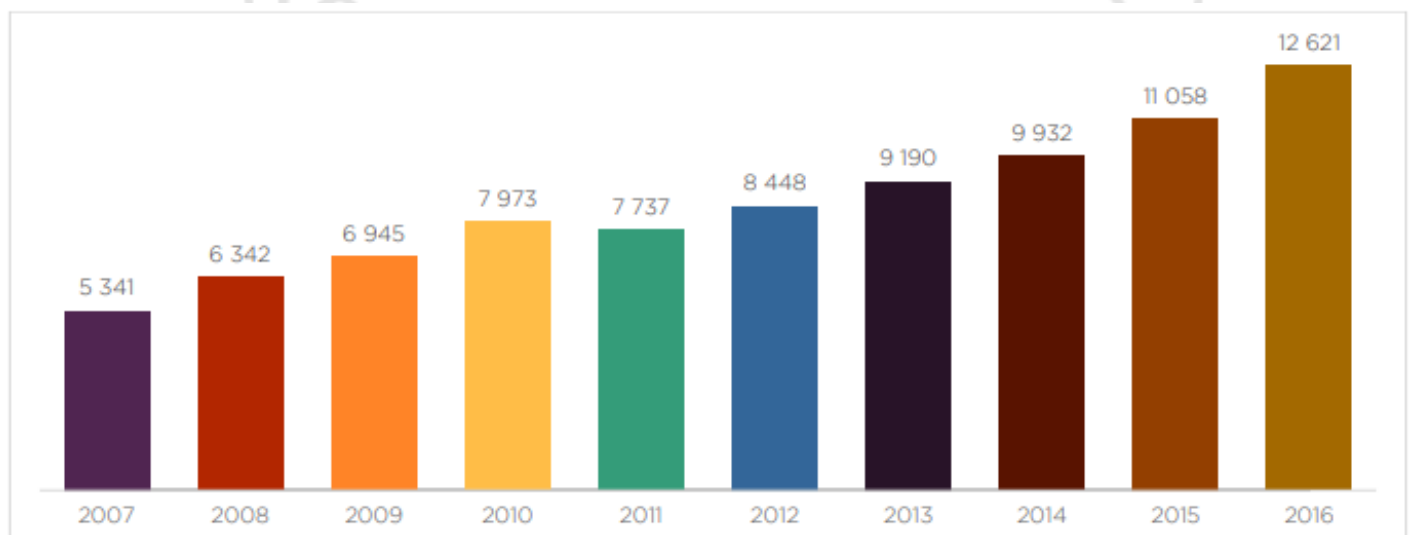

Fuente: MTC - OGPP - DGTT (2016)

Elaboración: MTC - OGPP - Oficina de Estadística 
Figura 2-4

\section{Plan vial Lima Metropolitana al 2020}

\begin{tabular}{|c|c|c|c|c|}
\hline Proyecto & Trayecto & $\mathrm{Km}$ & $\begin{array}{c}\text { Inversión en } \\
\text { millones }\end{array}$ & $\begin{array}{c}\text { Fecha de } \\
\text { culminación }\end{array}$ \\
\hline Línea 2 Metro de Lima & Plaza Central Ate-Plaza Garibaldi Callao & 35,0 & USD 6,500 & 2019 \\
\hline Vía Expresa Sur & Barranco-Panmericana Sur & 4,5 & USD 230 & 2018 \\
\hline Túneles Santa Rosa y San Martín & Cerro Santa Rosa & 2,0 & USD 50 & 2015 \\
\hline Vía Parque Rímac & Trébol de Javier Prado-Ovalo Habich & 9,0 & USD 700 & 2015 \\
\hline Vías Nuevas de Lima & Panamericana Norte-Puente Los Ángeles & 115 & USD 590 & 2016 \\
\hline
\end{tabular}

Fuente: Municipalidad de Lima (2016)

Elaborado por la Municipalidad de Lima

Este esperado aumento del parque automotor y de la inversión para el transporte público se ve reflejada también en todo el sector de Latinoamérica, donde en países con un menor crecimiento económico y con una población inclusive menor a la peruana, como es el caso de Chile, el parque automotor presenta una variación de hasta 3 veces más y un crecimiento mayor al del parque automotor peruano.

\section{Figura 2-5}

Venta de vehículos livianos y pesados en Latinoamérica

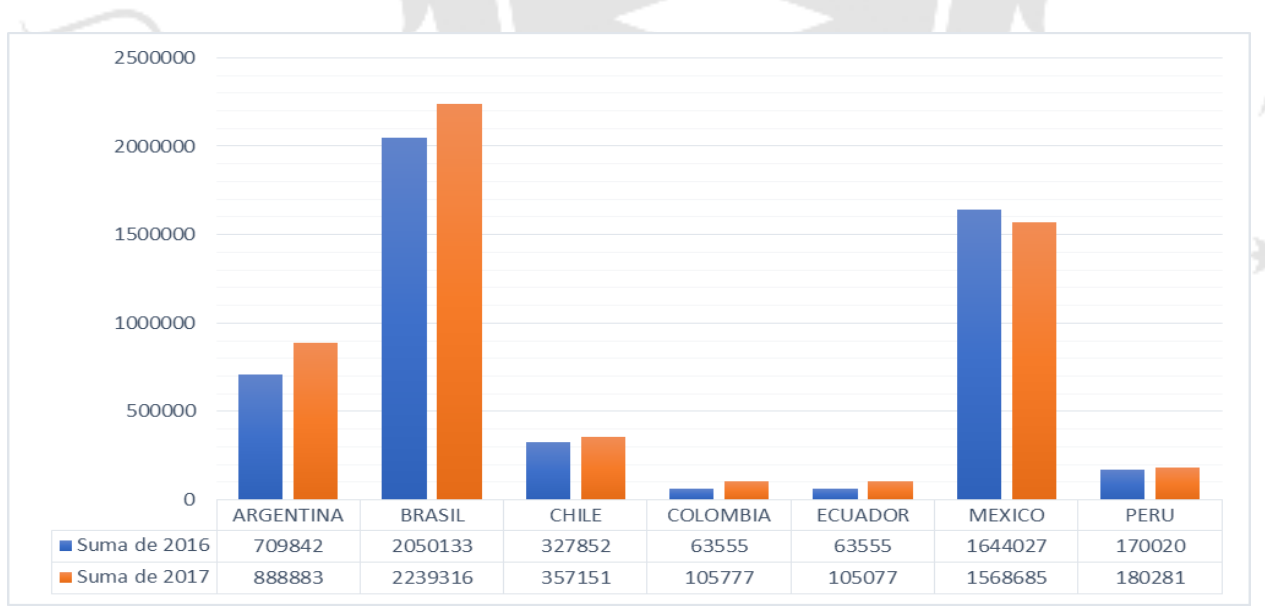

Fuente: AAP - MTC. (2017)

Elaboración Propia

\section{- Entorno social}


El crecimiento del parque automotor está relacionado también con la infraestructura vial, en este contexto el desarrollo de carreteras en Lima Metropolitana fomenta la inversión tanto pública como privada de vehículos pesados para el transporte público.

Es este aspecto, el social ligado al uso del transporte público en Lima al que le hemos prestado bastante atención debido al incremento de la demanda por parte de la población limeña en buses como el Metropolitano y vehículos interprovinciales para el transporte masivo de empresas privadas. Así en el siguiente gráfico elaborado por JICA en el año 2013 se observa el comportamiento en el transporte para los usuarios de Lima Metropolitana

\section{Figura 2-6}

\section{Distribución modal \% en Lima y Callao}

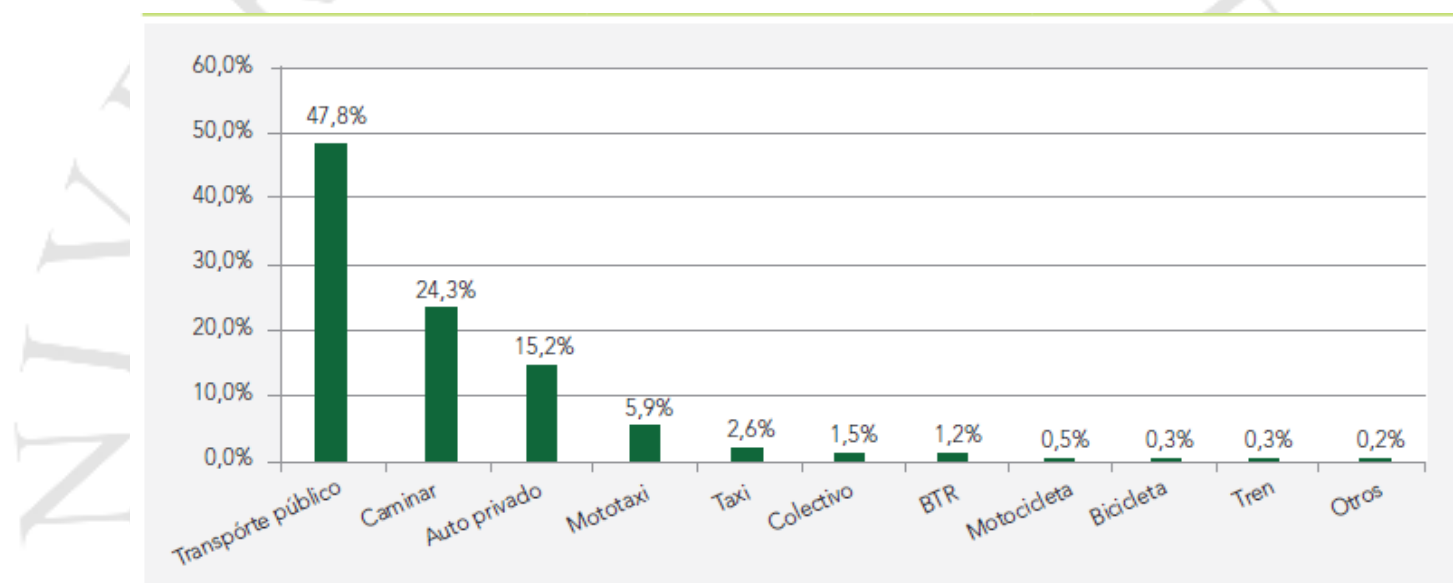

Fuente: AAP (2017)

Y en este siguiente gráfico elaborado por "Lima como Vamos" a mediados del 2017 se observa el crecimiento de la demanda del transporte público llegando a ocupar hasta el $75 \%$ de los viajes para los limeños. 


\section{Figura 2-7}

Distribución de los tipos de Viajes en Lima y Callao

\begin{tabular}{cc}
\hline $\begin{array}{c}\text { TRANSPORTE COLECTIVO } \\
73.3 \% \\
\text { Bus }\end{array}$ & $32.5 \%$ \\
\hline Combi o coaster & $27.9 \%$ \\
Metropolitano & $4.9 \%$ \\
Colectivo & $3.3 \%$ \\
Metro de Lima & $3.1 \%$ \\
Corredores & $1.6 \%$ \\
Complementarios &
\end{tabular}

\begin{tabular}{|c|c|}
\hline \multicolumn{2}{|c|}{$\begin{array}{c}\text { TRANSPORTE INDIVIDUAL } \\
16.6 \%\end{array}$} \\
\hline Automóvil propio & $9.4 \%$ \\
\hline Mototaxi & $4.2 \%$ \\
\hline Taxi & $2.0 \%$ \\
\hline Motocicleta propia & $1.0 \%$ \\
\hline
\end{tabular}
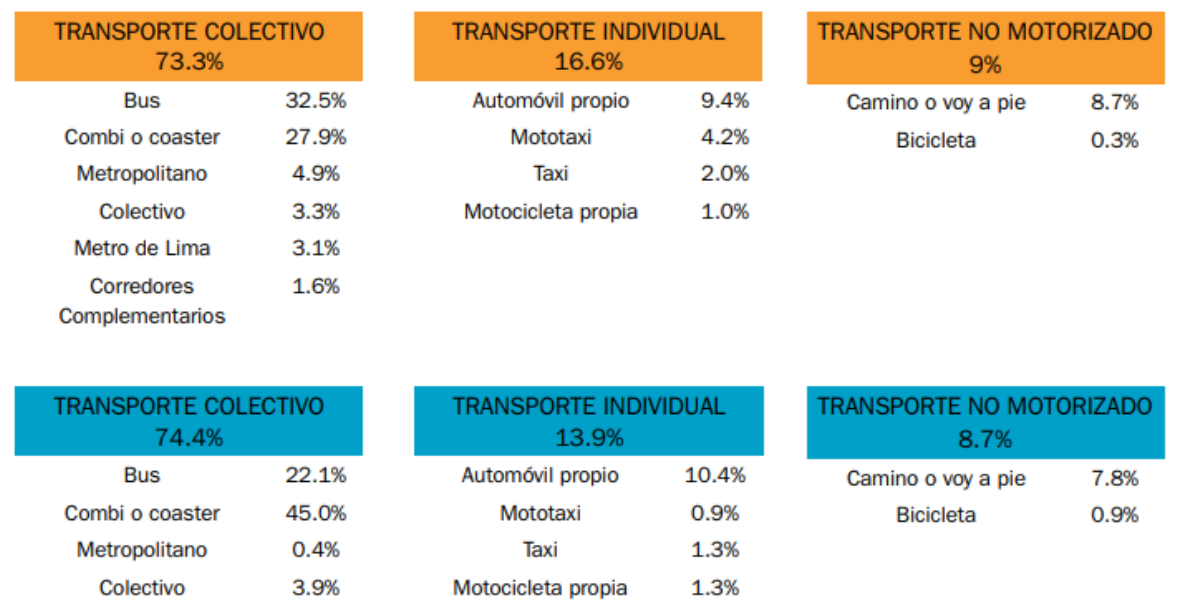

Metropolitano $\quad 0.4 \%$

Colectivo $\quad 3.9 \%$

Metro de Lima $\quad 2.6 \%$

Corredores $\quad 0.4 \%$

Complementarios

Mototaxi $\quad 0.9 \%$

Taxi $\quad 1.3 \%$

Motocicleta propia $\quad 1.3 \%$

Base: Total de entrevistados que estudia y/o trabaja fuera de casa

Fuente: INEI (2013)

LIMA CÓMO VAMOS

Como se observa, la competitividad y el crecimiento de la demanda de buses para el transporte público han hecho que la demanda de reparaciones y renovaciones se vea incrementada y se busque continuamente una empresa que ofrezca un servicio de calidad y de bajo precio al mismo tiempo.

\section{- Entorno legal}

"En el Perú se cuenta con varios beneficios legales y tributarios para la importación y comercialización de repuestos automotrices, debido a los tratados internacionales con países de gran producción como China, Corea y Estados unidos, que permiten que disminuyan los costos de las importaciones para brindar mejores precios a los consumidores, permitiéndoles la elección de diversas alternativas de productos para la accesibilidad del cliente, mostrando repuestos de calidad y a un menor precio." (Cardenas Moza, 2016)

De la misma forma, la facilidad de importación de materias primas directamente relacionadas con el negocio de "Industrias Carroceras Quispe" favorece que la empresa pueda reducir sus precios y elevar la calidad de sus carrocerías al conseguir los insumos necesarios a menor precio debido a la disminución de impuestos 
arancelarios. De la misma forma, el negocio de reparaciones y remodelaciones se ve directamente influenciado con la promulgación de decretos y ordenanzas municipales para la circulación de vehículos de transporte públicos, como es en el caso del Decreto Supremo $\mathrm{N}^{\circ}$ 058-2003-MTC en el que se brinda requisitos destinados a las dimensiones en las carrocerías de buses interdistritales y de transporte escolar.

\section{- Entorno tecnológico}

La globalización ha sido determinante a lo largo de los años para la innovación de nuevas tecnologías en todas las industrias, y no solo eso, los procesos también han sido afectados para buscar optimizar los costos de producción. Así, los sistemas internos han sido modificados para acoplar piezas y componentes de mayor performance; y, en su gran mayoría el sistema mecánico ha sido desplazado por el sistema eléctrico y electrónico. Por esta razón la necesidad de nuevos repuestos de alta tecnología ha tenido una fuerte demanda en el Perú en los últimos años, como consta la siguiente investigación de la Asociación Automotriz del Perú.

\section{Figura 2-8}

Importación de suministros

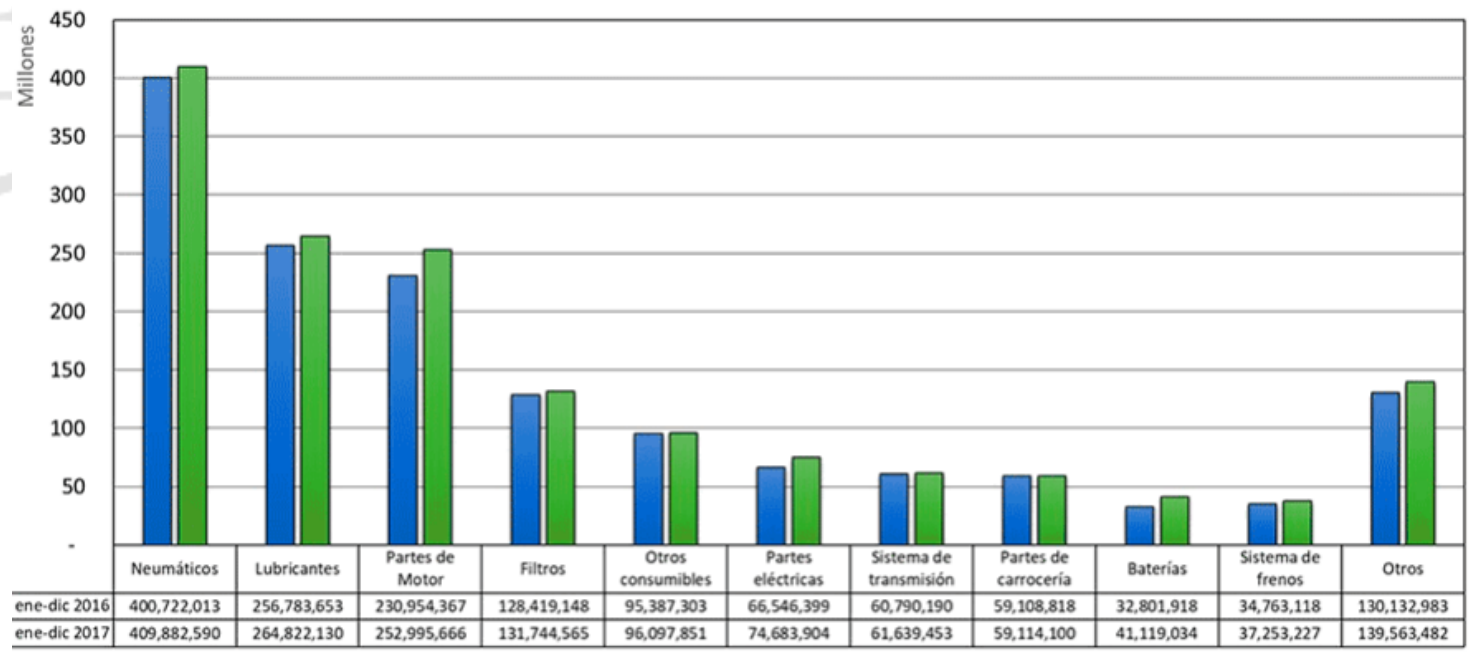

ESTADISTICA DE IMPORTACIÓN DE SUMINISTROS. En el gráfico se muestra el valor FOB (US\$) de la importación de suministros acumulado a diciembre 2017 .

Fuente: AAP (2017)

La tecnología en reparación automotriz innova constantemente, implementando nuevos sistemas y herramientas que hacen posible la reparación de estos pequeños daños sin necesidad de recurrir a los procesos de pintura, y esto se constata también con el cada vez más constante incremento de importación de repuestos eléctricos y electrónicos. 
La tecnología que ahora poseen los sistemas internos de los vehículos nuevos ha desencadenado una serie de factores para el sector automotor, además la cada vez más cambiante innovación en materiales para carrocerías ha desencadenado que los talleres de reparación estén atentos a las nuevas posibilidades que estos materiales ofrecen. Como ejemplo la empresa Honda ha investigado una nueva tecnología con la que es capaz de unir paneles de aluminio con paneles de acero en la carrocería de sus coches. "El beneficio de esto es evidente: con esta técnica pueden alcanzar reducciones de peso cercanas al 17\% en ciertos componentes como las puertas del vehículo, etc.” (Motor Pasion, 2015)

Como se explicó anteriormente, los servicios que ofrece la empresa Industria Carrocera Quispe SAC son de reparación de buses siniestrados, fabricación de carrocerías para buses nuevos o pintura general de buses nuevos, seminuevos o deteriorados.

El servicio de reparación de buses siniestrados, generalmente, es ofrecido a los clientes que cuentan con buses asegurados. Es decir, el propietario de dicho bus se encuentra afiliado a una compañía de seguros que cubre cualquier accidente que pueda tener el bus dentro de su ruta, por lo que se tiene un especial cuidado en innovar con nuevas técnicas de pintado o refaccionado que conlleven a un mayor ahorro en el costo de servicio.

\subsection{Análisis del entorno competitivo}

Para realizar el análisis externo de la empresa, se empleará una herramienta llamada las cinco fuerzas de Porter.

- Rivalidad de competidores

Se cuenta con una alta rivalidad entre competidores, debido a que, la empresa se encuentra en un mercado maduro, el cual, comenzó con la llegada del transporte interprovincial al Perú, con más de 10 años de antigüedad. Es por eso, que existen diferentes niveles de competidores, es decir, hay talleres pequeños que ofrecen el servicio de reparación de buses siniestrados; al igual que, otros talleres con mayores niveles de organización, como la empresa LEQUI S.A.C., la cual es una de las que lidera este sector. Además, el rubro en el que se encuentra la empresa, mantiene un elevado costo fijo y costo de almacenamiento 
- Poder de proveedores

Se cuenta con un bajo poder de proveedores, ya que, existe una amplia cantidad de distribuidores que ofrecen los materiales que se emplean para la reparación de los buses; $\mathrm{y}$, básicamente, los precios de dichos proveedores no varían mucho, y es por esto, que el poder de los proveedores es bajo.

- Poder de compradores

Se cuenta con un alto poder de compradores, dado que, el volumen de compras que realizan es considerable, es decir, el servicio que se ofrece tiene un precio un poco elevado, pero menor en relación a sus otros competidores. Además, existe una posibilidad latente de que los clientes se integren hacia atrás, es decir, contratar a personal especializado para que le ofrezcan el mismo servicio que ofrece la empresa.

- Amenaza de nuevos ingresos

Se cuenta con una baja amenaza de nuevos ingresos, debido a que, las barreras de entradas son elevadas, es decir, el capital necesario para empezar una empresa de servicios como la que estamos analizando es elevada, por dos motivos. El primero, es el alto costo que implica tener un taller de las dimensiones necesarias para realizar los procesos; y el segundo, el valor y la complejidad de los insumos que se emplean para realizar todas las operaciones, son, según nuestra perspectiva, el reto más grande que deben superar los nuevos ingresantes.

- Amenaza de productos sustitutos

Se cuenta con una baja amenaza de productos sustitutos, ya que, el servicio es diferenciado y especializado, es por eso, que cualquier otro competidor ofrece el mismo servicio de reparación de buses siniestrados. 


\section{Figura 2-9}

Fuerzas de Porter

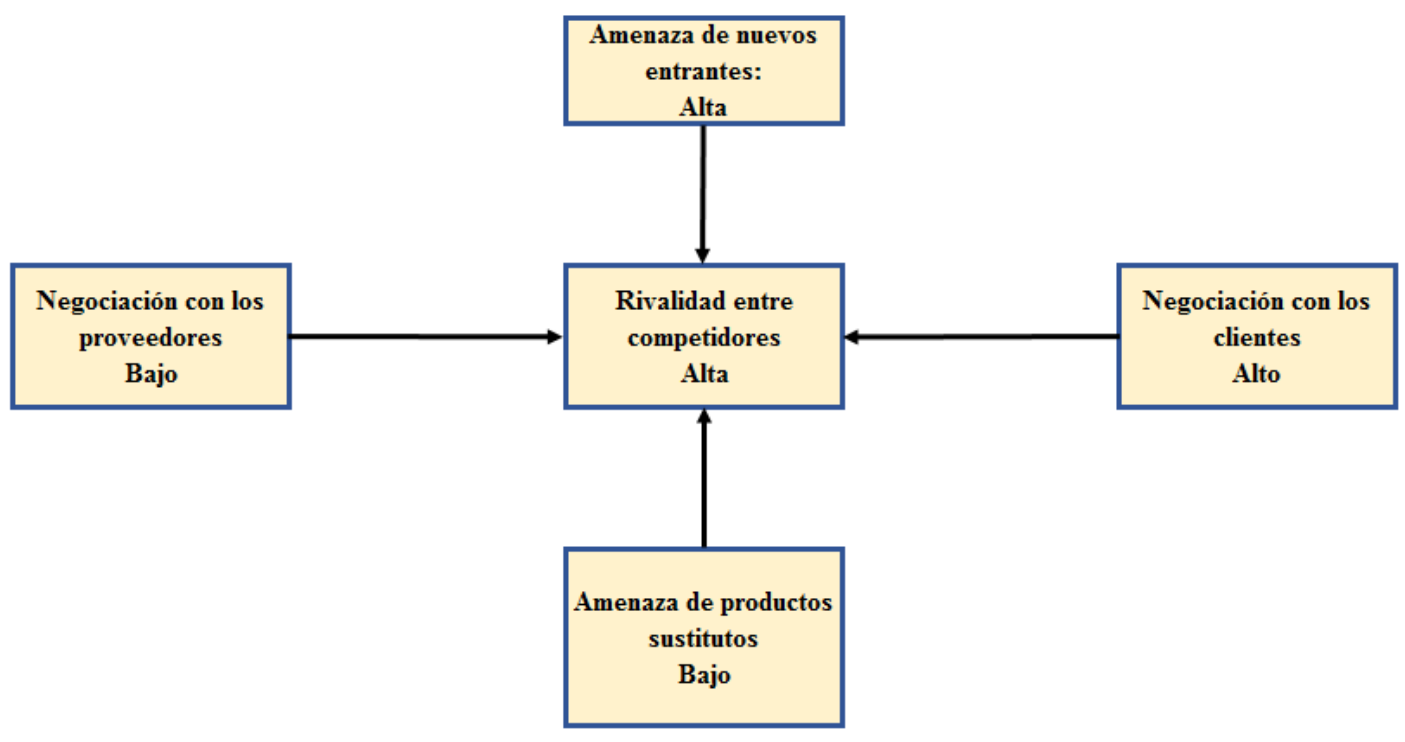

Fuente: Estrategias Competitivas (2016)

Elaboración propia

\subsection{Identificación y evaluación de las oportunidades y amenazas del entorno}

\section{Oportunidades}

Las oportunidades más resaltantes que se presenta en el rubro del mantenimiento de unidades que ofrecen el servicio de transporte urbano, se enfocan en la modernización gracias al fenómeno de la globalización.

- Modernización de la flota de buses urbanos e interprovinciales

La mayoría de las empresas que brindan el servicio de transporte urbano e interprovincial se sienten obligadas a comprar o modernizar las unidades, debido a que el apartado estético es de suma importancia para los pasajeros al momento de tomar la decisión de que empresa escoger para viajar a su destino.

Dentro del apartado estético, lo que más sobresale es la calidad del pintado, porque esto refleja o aparenta que tan nuevo es la unidad; porque no es lo mismo viajar en una unidad que está mal pintada y por ende parece antigua y poco segura, a otra que tiene la pintura de una calidad superior que desprende seguridad, modernidad y comodidad. Otro aspecto a tratar, es la calidad de los asientos en los que se brinda el 
servicio de transporte, porque se debe ser considerado con las personas que viajan en este medio de transporte, dado que, si el asiento donde pasarás todo el tiempo de tu viaje no se encuentra en óptimas condiciones, esto podría causar un daño en la salud del pasajero. Es por esto que las empresas tratan de corregir o cambiar los asientos defectuosos de sus unidades de transporte, y de esta forma, la empresa industria carrocera Quispe S.A.C. encuentra una oportunidad de ampliar su cartera de clientes y la cantidad de servicios que ofrece.

Gracias a las fortalezas que posee la empresa en estudio, las empresas de transporte urbano e interprovincial la toman en cuenta al momento de buscar una empresa de carrocería que les ayude a modernizar sus unidades.

\section{Figura 2-10}

Asientos reclinables de ómnibus interprovincial

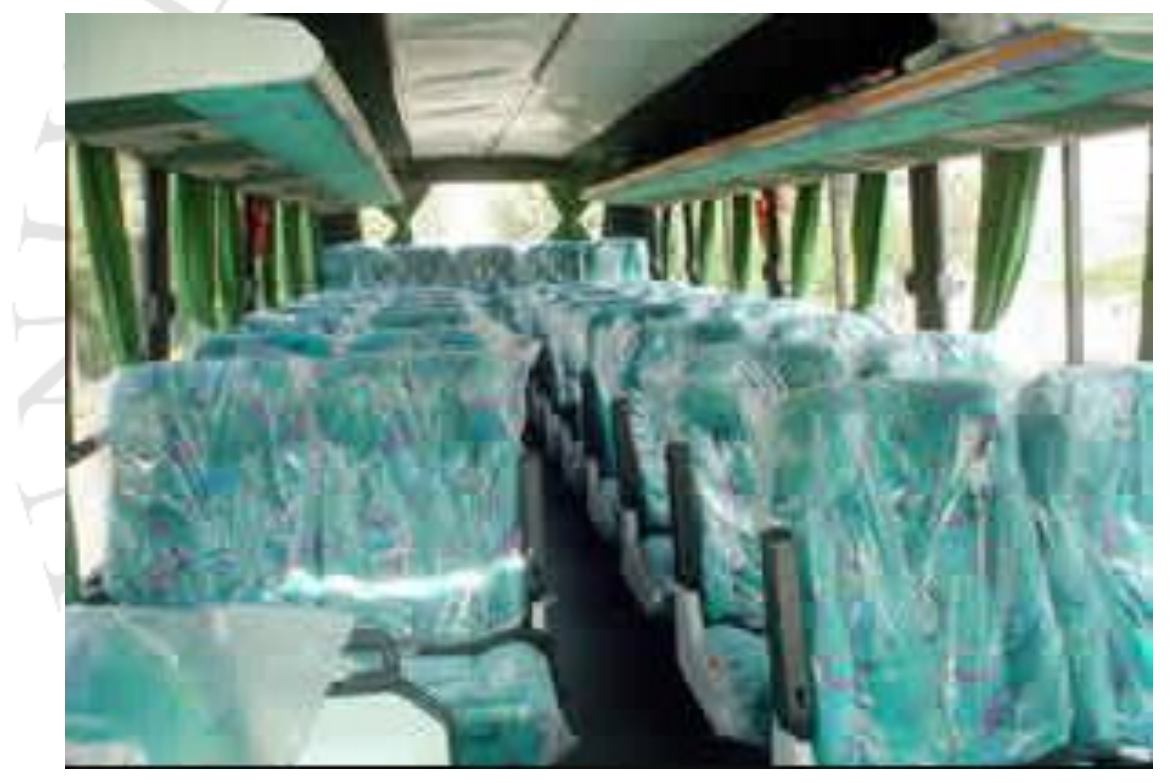

Fuente: Industria Carrocera Quispe S.A.C. (2017)

Elaboración propia 


\section{Figura 2-11}

Ómnibus de la empresa JAKSA

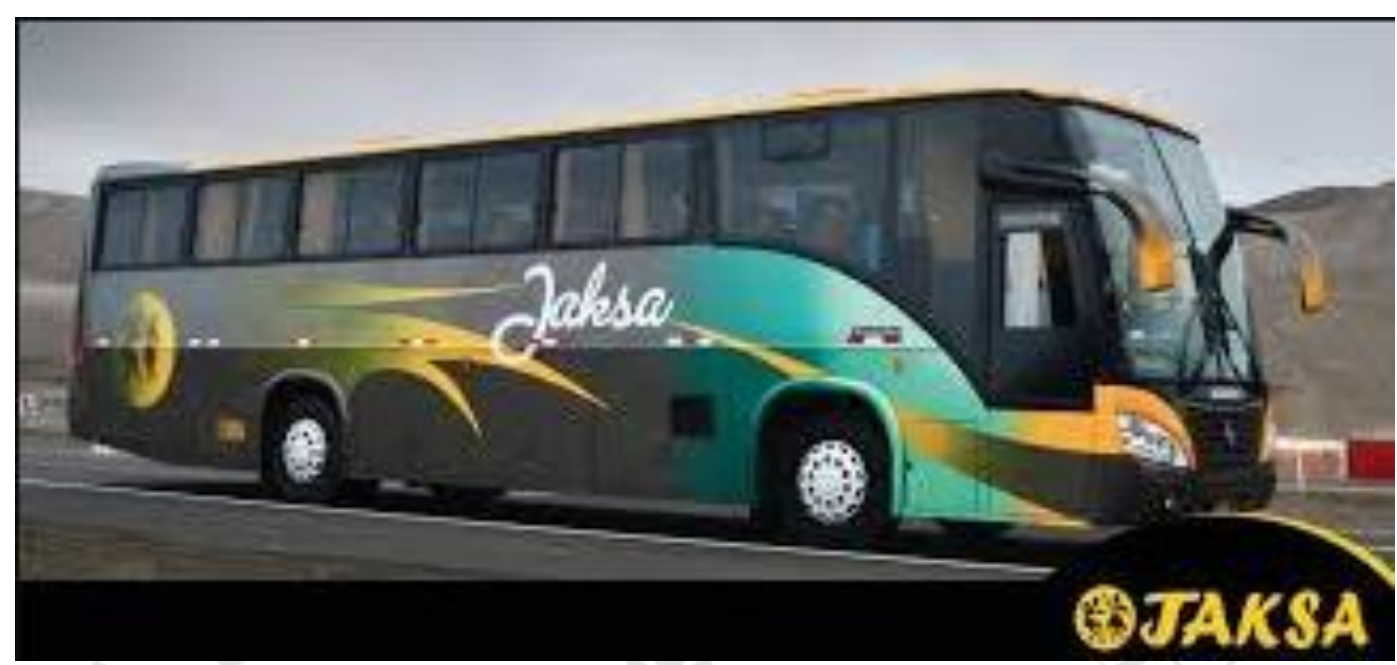

Fuente: Info de buses (2014)

- Cumplimiento con las revisiones según ley

El estado peruano mediante sus órganos independientes, como el Ministerio de transportes y comunicaciones, controlan que las unidades que brindan el servicio de transporte público e interprovincial cuenten con las revisiones técnicas vehiculares, el seguro obligatorio contra accidentes de tránsito (SOAT), tarjeta de circulación, su tarjeta de propiedad y, en algunos casos, las empresas cuentan con una CIA. de seguro particular contra accidentes. El motivo de todas estas evaluaciones es para asegurar la seguridad de las personas durante el viaje a su destino final.

Así como mencionamos que el apartado estético era de suma importancia para los pasajeros, consideramos que la seguridad es un factor igual de importante, es por esto, que las empresas realizan diferentes mantenimientos a las unidades; por ejemplo, se realiza un mantenimiento preventivo a las llantas, un mantenimiento correctivo al sistema eléctrico y un mantenimiento reactivo a las autopartes de fibra y al apartado de la carrocería.

A pesar de todas estas medidas, la cantidad de accidentes de tránsito no han variado mucho, como se podrá observar en el siguiente gráfico, en el cual, arroja resultados poco alentadores, dado que, el número de personas que perdieron la vida a causa de un accidente de tránsito ha disminuido solo el 18.82\% entre los años 2006 y 2017. Pero es innegable que, en el pasado, el transporte interprovincial informal causó 
muchos accidentes por el hecho que no existía ningún control del estado de la unidad que brindaba el servicio de transporte.

\section{Figura 2-12}

Muertos por accidentes de tránsito 2006 - 2017

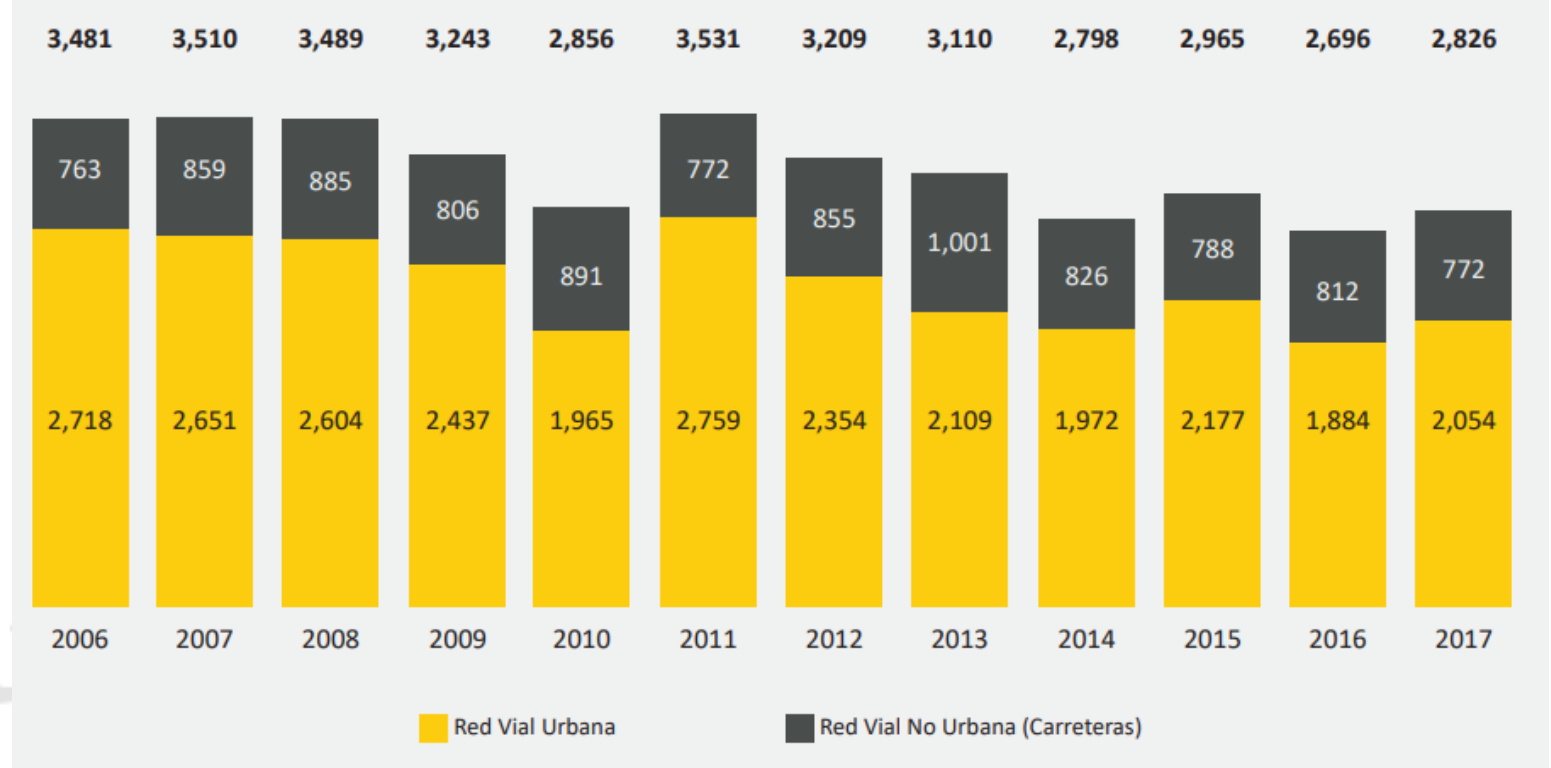

Fuente: MTC - Secretaría Técnica del consejo nacional de seguridad vial (2017)

- Reforma del transporte

Una de las oportunidades que encontró la empresa para encaminarse en el sector del transporte, fue el comienzo de la reforma del transporte, la cual, consiste en el retiro de unidades antiguas de transporte urbano que todavía se encontraban en circulación, y que generaban niveles altos de contaminación y ofrecen un paupérrimo servicio. Por lo cual, la Municipalidad de Lima creó un ente regulador que se encargue de planificar, implementar, administrar y mantener que las unidades se e encuentren en óptimas condiciones; es por eso que, en el año 2014, nació el Instituto Metropolitano Protransporte de Lima (PROTRANSPORTE, 2018).

Gracias a esta reforma y a la alianza con las empresas de transporte que seguían la ruta San Juan de Lurigancho - Abancay, la cantidad de trabajo ha aumentado en los últimos meses, dado que, la municipalidad decidió implementar las unidades que operaban en las diferentes empresas para que el personal que laboraba no se vea afectada, y por consiguiente, se tuve que repotenciar estas unidades para que cumplan con los estándares de calidad que propuso Protransporte para obtener el tan ansiado transporte de calidad. 


\section{Figura 2-13}

Corredor morado

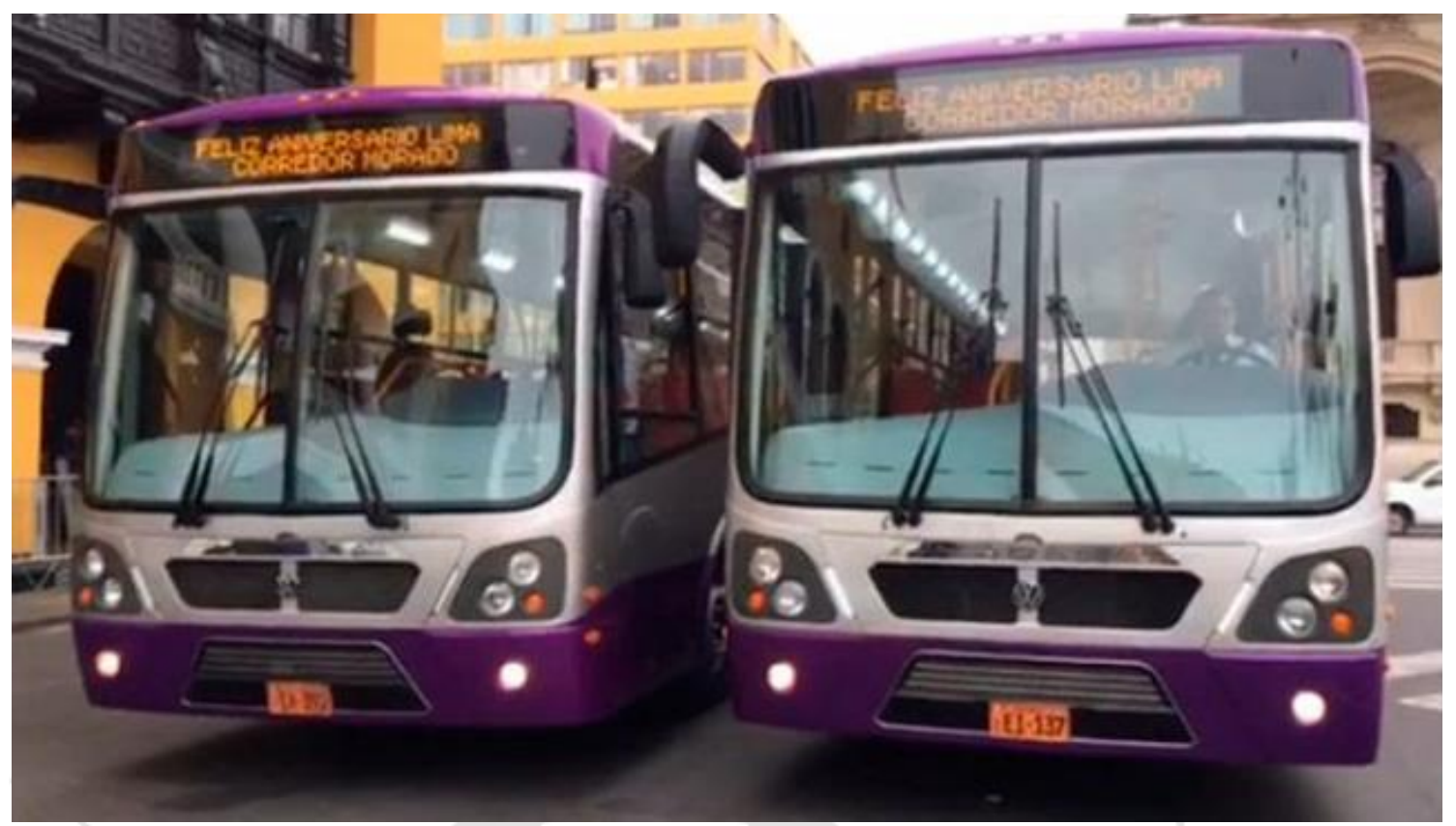

Fuente: La Republica (2017)

\section{Amenazas}

Las amenazas que se han podido identificar para la empresa industria carrocera Quispe S.A.C., serán detalladas a continuación.

- Importación de buses nuevos

La empresa Industria Carrocera Quispe S.A.C. gracias a sus fortalezas tiene varias oportunidades de crecimiento en el sector, sin embargo, existen acciones externas que se toman que impiden un crecimiento constante de dicha empresa.

La amenaza más resaltante es la adquisición de buses 0 kilómetros provenientes del extranjero, de países como Brasil y China. Se mencionan estos dos países porque son los principales fabricantes de ómnibus, ya que, en Brasil se encuentra la empresa más grande en este rubro a nivel mundial, la cual es Marcopolo. Por otro lado, en China, se convierte también en una potencia en este rubro gracias a sus costos bajos de producción.

Realizando una comparación entre estos dos países potencia, podemos observar que, en Brasil, producen con altos estándares de calidad, tanto en la forma de producción como en los suministros que utilizan, lo cual conlleva a un precio más elevado. Mientras que, en China, te ofrecen precios más económicos, pero con la premisa de que, el tiempo de 
durabilidad será menor que el que te ofrece la empresa Marcopolo. Por ende, se necesitará una mayor cantidad de repuestos para cuando ocurra una falla en el funcionamiento, los cuales son difíciles de encontrar por lo comercial que son.

\section{Figura 2-14}

\section{Importación de vehículos pesados}

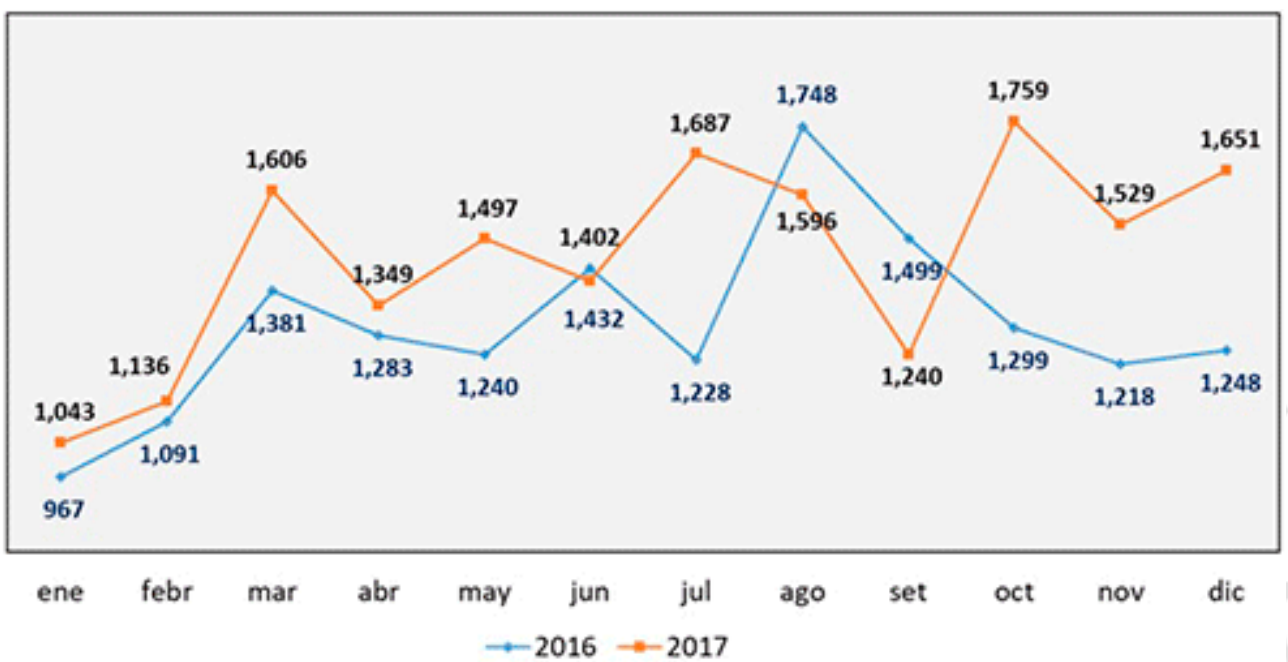

Fuente: SUNAT-AAP (2018)

- Existencia de empresas informales del mismo rubro

Para competir en este sector, los empresarios formales deben contar con un respaldo económico considerable, dado que, las barreras de entrada que constan de instalaciones, maquinaria, mano de obra y suministros, poseen un costo elevado. Asimismo, muchos deciden residir en la informalidad, en la cual, evaden el pago de impuestos por los trabajos realizados, la mano de obra que contratan no manejan el conocimiento necesario para realizar los procesos de manera eficiente, y la maquinaria y suministros que utilizan se encuentran deteriorada y en condiciones deplorables.

Por consiguiente, se ha generado un sentido de desconfianza de parte de los dueños de las unidades, debido a las malas experiencias de haber contratado trabajos en talleres informales, los cuales no cuentan con el "know how" necesario para realizar estos procesos de forma eficiente y eficaz; es por eso, que algunos empresarios que se dedican a este rubro de transportes, optan por la importación de buses nuevos, antes que la fabricación de estos a mano de empresas peruanas. En la siguiente imagen se podrá observar como ha ido aumentando la importanción de los omnibuses en el Perú. 


\section{Capítulo III. Diagnóstico del proceso estratégico}

\subsection{Análisis del Proceso Estratégico}

\subsubsection{Análisis del direccionamiento estratégico: visión, misión y objetivos organizacionales}

- Misión

Ser reconocidos como una de las principales empresas en el país en reparación de buses siniestrados y construcción de carrocerías por nuestra atención de calidad.

- Visión

Somos una empresa dedicada a la fabricación de carrocerías metálicas para buses urbanos e interprovinciales, que busca desarrollar soluciones integrales en cuanto al diseño y construcción, a través del uso de la tecnología adecuada, innovación en nuestros procesos constructivos y satisfacción de los requerimientos que tiene cada uno de nuestros clientes.

- Objetivos organizacionales

a) Incrementar la rentabilidad neta de la empresa

b) Aumentar la capacitación de los operarios para evitar costos por mal uso de las herramientas de trabajo.

c) Establecer un ambiente de trabajo óptimo para las labores a realizarse, aumentando la seguridad para los trabajadores y para eliminar tiempos muertos.

\subsubsection{Análisis de la estrategia general de la empresa}

La ventaja competitiva que mantiene Carrocerías Quispe y lo que los ha ayudado a crecer y posicionarse en el mercado se debe en gran parte al desarrollo y la implementación de una estrategia genérica aplicada a toda la empresa, la que se analizará a continuación:

Para determinar qué estrategia se aplica es importante primero identificar el ámbito competitivo en el que Carrocerías Quispe se enfoca. Debido a que el único canal de distribución en Lima Metropolitana es el ubicado en Ate-Vitarte y también porque el 
servicio ofrecido está dirigido hacia una parte del sector automotor se puede concluir que la empresa tiene un ámbito competitivo reducido.

\section{Figura 3-1}

\section{Estrategia genérica}

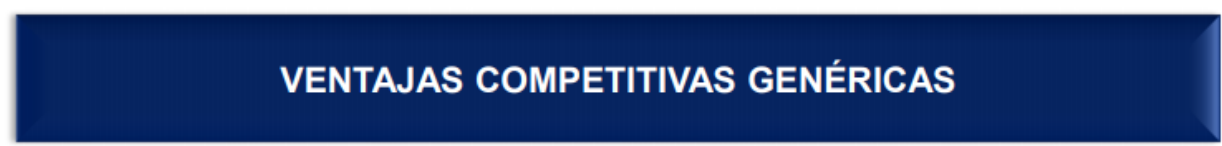

COSTE DIFERENCIACIÓN
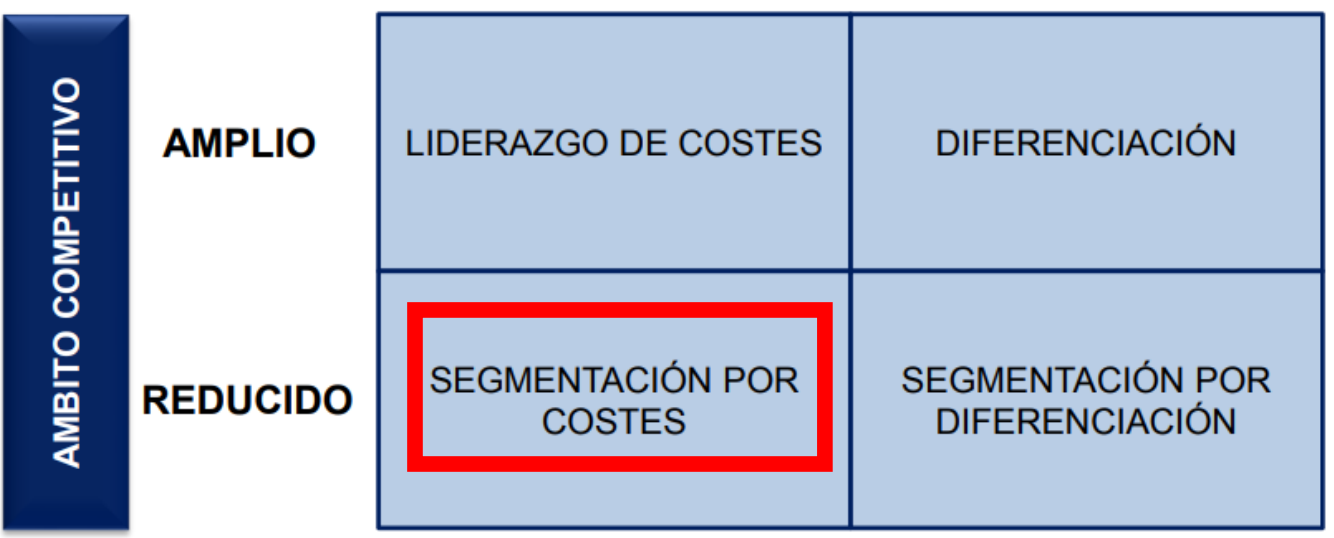

Fuente: Estrategias competitivas (2016)

Elaboración Propia

El segundo paso es entender qué ventaja estratégica posee, para ello existen 2 posibilidades: la singularidad percibida por el consumidor y la posición de bajos costos. Al entrevistar a el gerente y trabajadores de la empresa, se puede llegar a la conclusión de que la empresa aplica segmentación por costes porque ofrece uno de los más bajos precios en el mercado por arreglar la carrocería de buses.

\subsubsection{Análisis de la estructura organizacional de la empresa}

\section{- Gerente general}

Es el encargado de administrar todos los ingresos y egresos que presenta la empresa al momento de realizar sus operaciones, además, se encarga de distribuir eficazmente todos los activos entre las distintas áreas internas. En la actualidad, el gerente general es el señor Víctor Quispe Huillca.

\section{- Supervisor de planta}


Es la persona que se encarga de revisar que los operarios estén cumpliendo con su rol en la organización, también es el nexo entre el gerente general y los jefes de las distintas áreas que tiene la empresa. Actualmente el supervisor de planta, quien es la segunda persona con mayor experiencia dentro de la empresa, es el señor Hugo Caldas.

\section{- Secretaria}

Es la encargada de tener una comunicación ininterrumpida con el gerente general, debido a que se encarga también del aspecto comercial de la empresa. Es decir, es la persona que realiza los contratos con los clientes cuando el gerente general no se encuentra presente, pero con la previa aprobación de este. Esta persona también cuenta con una extensa cantidad de años presentes en la empresa, su nombre es Soledad Arméstar.

\section{- Jefe de carrocería}

Es el encargado de realizar y supervisar que sus colaboradores desempeñen adecuadamente sus responsabilidades como el soldado de las estructuras metálicas, la remodelación de los accesorios o zonas del bus y la reparación de algunas zonas de la carrocería en el caso de los siniestros que también atiende la empresa Industria Carrocera Quispe S.A.C. El presente cargo actualmente lo está desempeñando el señor Exaltación Quispe Peña.

\section{- Jefe de enfibrado}

Se encarga de supervisar que los operarios de fibra de vidrio realicen los requerimientos de los carroceros y del área comercial, es decir, si el carrocero necesita avanzar con la parte superior del bus, entonces necesitará de diferentes recursos entre esos están la fibra de vidrio que cubrirá la parte exterior del bus. Esta persona acompaña al señor Quispe alrededor de dieciséis años. Es decir, antes de formalizar cualquiera de las dos empresas que posee el señor Quispe hasta el momento. El nombre de este señor es Milqueades Huillca.

\section{- Jefe de pintado}

Es la persona encargada de realizar los trabajos de pintado en la empresa, la cual consiste en la última parte del proceso de fabricación del bus como sello distintivo 
de la empresa. Además, se encarga de dar algunos paños de pintura en los buses siniestrados que llegan a la empresa. En la actualidad el presente cargo lo ocupa el señor Yeymi Amao.

\section{- Jefe de almacén}

Es el encargado de contabilizar los insumos, repuestos y materiales que entran y salen de los almacenes de la empresa, es decir, por cada insumo que necesita el jefe de carrocería o el de pintado; es el jefe de almacén el encargado de proveerle estos materiales. Además, mantiene una comunicación con los proveedores de la empresa para solicitar la cantidad necesaria de insumo que requieran en algún momento en particular. El jefe de almacén actual es la señorita Baneza Accostupa.

\section{Figura 3-2}

\section{Organigrama de la empresa}

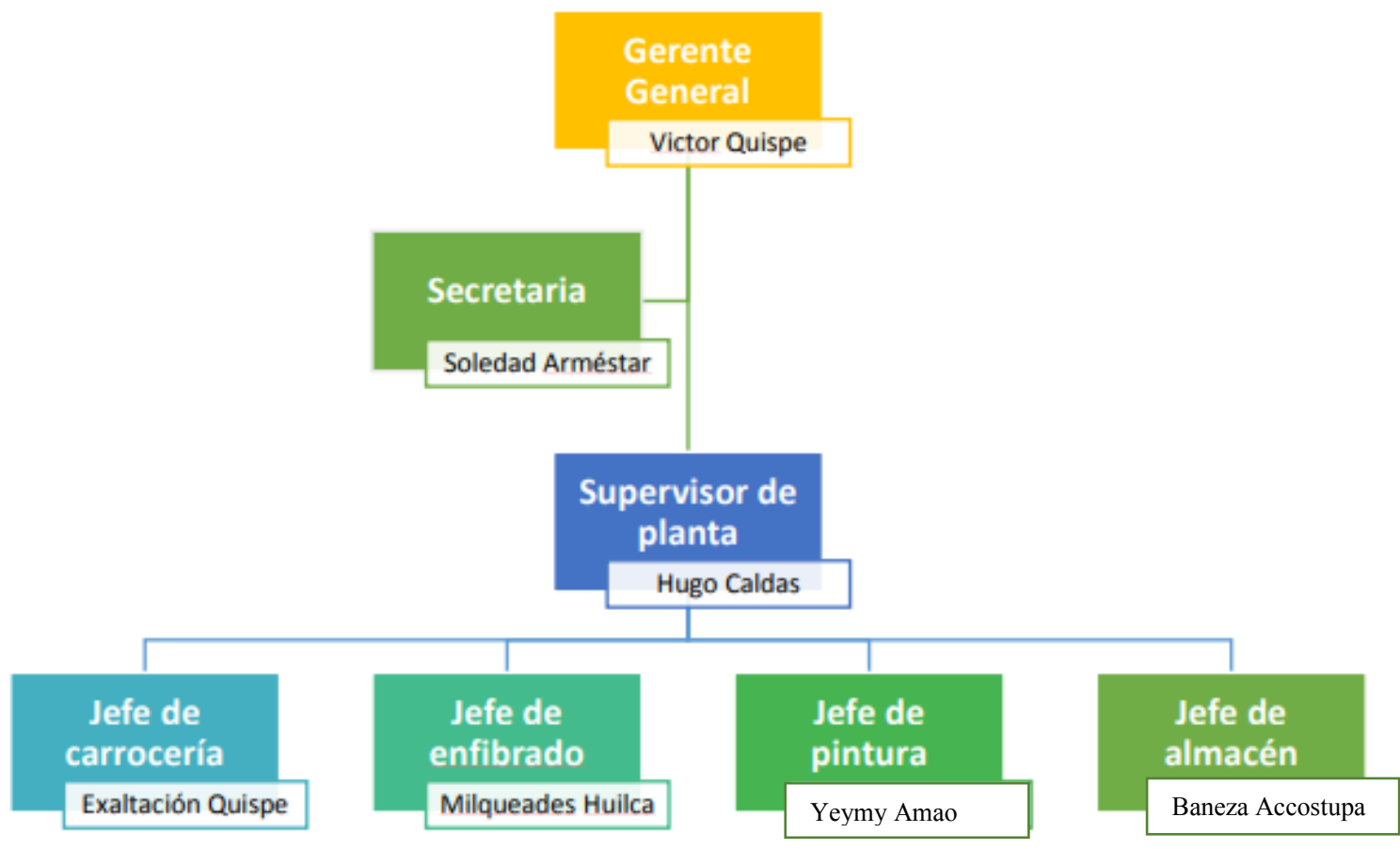

Fuente Industrias Carroceras Quispe (2017)

Elaborado por Quispe \& Contreras. 


\section{Capítulo IV. Diagnóstico del Proceso Comercial}

\subsection{Estudio de mercado}

\subsubsection{Descripción del cliente y consumidor}

Las necesidades de los clientes representan el punto de partida en el desarrollo, diseño e implementación de cada proyecto realizado (Ita, 2013).

Basándonos en lo anterior, podemos concluir que los clientes principales que tiene la empresa Industria Carrocera Quispe S.A.C. son aquellas empresas que poseen vehículos pesados, como son, los ómnibus interprovinciales o urbanos. Asimismo, los microbuses que cuentan con seguro contra accidentes y sufren del algún siniestro, son llevados al taller de la empresa en estudio; es por esto, que el mayor porcentaje de las ventas, está asumida por las compañías de seguros. A continuación, se enlistará la cartera de clientes que tiene la empresa.

- La positiva seguros y reaseguros

- Rímac seguros y reaseguros

- Transporte Huáscar

- Empresa de transporte la 23

- Divecenter

- Transporte de personal Arellano S.A.C.

\subsubsection{Descripción comercial de productos o servicios}

Los servicios que ofrece la empresa Industria Carrocera Quispe S.A.C. se encuentran enfocados en el mantenimiento automotriz de los vehículos pesados que prestan el servicio de transporte urbano o interprovincial. Los principales servicios que se ofrecen son:

- Pintado

Servicio el cual consta de un recubrimiento del vehículo con una capa fina de pintura y barniz para prevenir de corrosión al metal. Además, permite decorar y embellecer al bus de transporte. 
- Planchado

Servicio que consta de un alineamiento de la estructura metálica de los buses que se encuentran siniestrados por algún accidente que han sufrido.

- Servicio eléctrico

Se brinda cuando el sistema eléctrico del bus se encuentra dañado o necesita alguna revisión por el técnico.

- Carrocería

Se brinda cuando la estructura metálica del chasis o de la coraza ha sufrido algún daño, el cual, perjudique el correcto funcionamiento de la unidad.

- $\quad$ Fibra de vidrio

Las autopartes de los buses urbanos e interprovinciales están hechas de fibra de vidrio y resina poliuretano. Por ende, cuando las unidades sufren un accidente, es inevitable dañar las autopartes de fibra; por lo cual, la empresa también brinda la venta de estas autopartes o la reparación de estas.

\subsubsection{Descripción de la demanda y oferta}

La demanda de un servicio es muy complicada calcularla, debido a que, a diferencia de un producto, no se puede estandarizar los servicios que se ofrecen. Es decir, el planchado de un bus siniestrado por la parte trasera no cuesta igual que el planchado de un ómnibus siniestrado por la parte delantera; dado que, la gravedad, los recursos a emplear, el tiempo necesario y las dimensiones son algunos de los puntos que impiden una estandarización en el servicio que se espera brindar.

Para la empresa en estudio, se pudo estimar una demanda del S/.707400, considerando los datos de ventas obtenidos del mes de mayo del 2018.

Por otro parte, la estimación de la oferta de la empresa Industria Carrocera Quispe S.A.C. se basa en el espacio que tiene la planta. Es por esto, que se pudo hallar que la oferta de la empresa es de 28 buses reparado por mes, teniendo en consideración, los espacios que se emplean para estacionar los buses siniestrados y así, se pueda desarrollar el mantenimiento automotriz de los vehículos. 


\subsection{Análisis del proceso comercial}

\subsubsection{Análisis de resultados comerciales}

Al momento de hacer un análisis relacionado al sector automotor peruano se encuentran siempre variaciones inesperadas en las proyecciones debido a la inestabilidad de este mercado. Por ejemplo, solo a inicios de este año se inició con una caída de $6.7 \%$ en la venta de vehículos nuevos. Edwin Derteano explicó al diario gestión que "Cuando una economía es sólida, la venta de vehículos va hacia arriba, porque hay personas, mercadería, recursos y maquinaria que movilizar; y, a pesar de esta caída ocasionada por el constante ruido político, se espera un alza en los siguientes meses" (Asociación Peruana Automotriz, 2018)

En efecto, al analizar resultados comerciales en la empresa Industrias Carroceras Quispe, las ventas generalmente guardan relación con el esfuerzo de la empresa por expandirse y por la inversión en gastos de venta; sin embargo, también resalta el continuo incremento del mercado de vehículos pesados en el Perú durante los últimos años, como se muestra en la figura a continuación.

\section{Figura 4-1}

Venta e inmatriculación de buses: 2017 hasta abril 2018

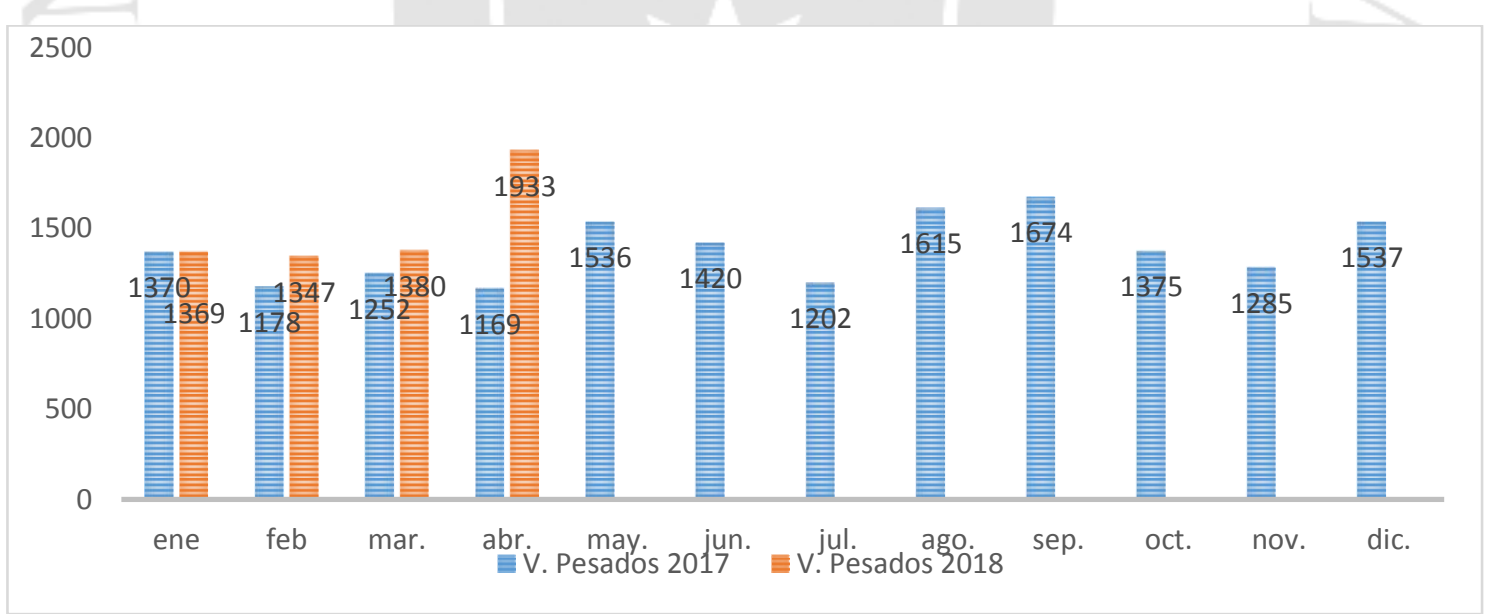

Fuente: AAP \& SUNAT (2018)

Elaboración propia

Como se observa, según las cifras proporcionadas por la Asociación Automotriz del Perú la venta de mensual de vehículos pesados ha aumentado con respecto al mes evaluado en el año anterior; y no solo eso, en otras cifras publicadas también por la SUNAT y en colaboración con la AAP, se observa también un aumento 
lineal considerable en las cantidades vendidas de buses desde el 2017 hasta abril del 2018.

\section{Figura 4-2}

Venta e inmatriculación de buses: 2017 hasta abril 2018

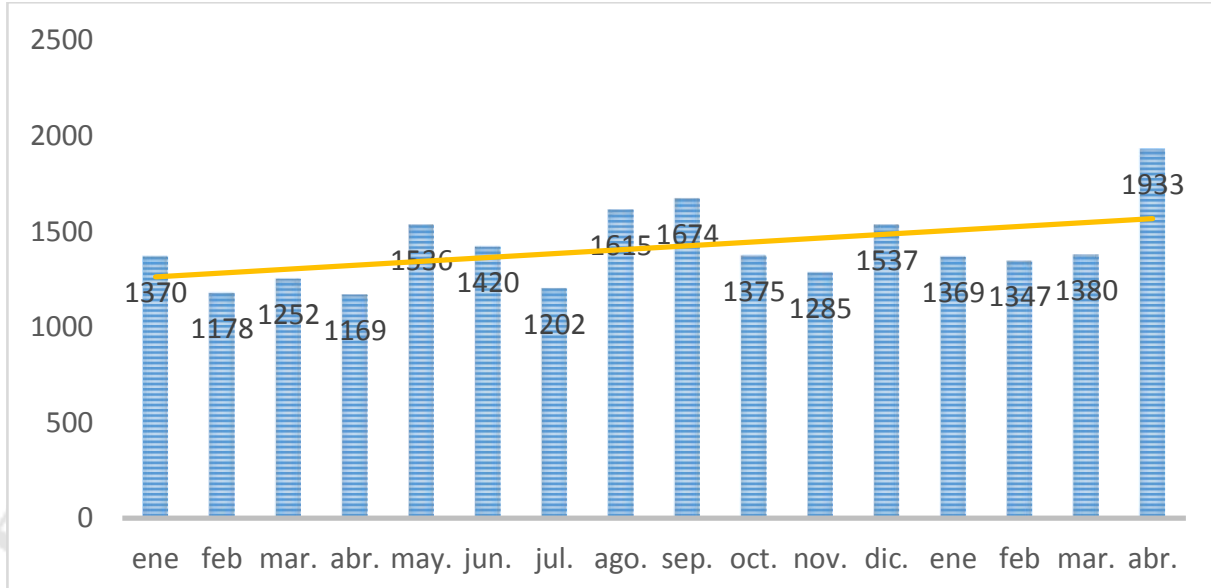

Fuente: AAP \& SUNAT (2018)

Elaboración propia

La línea amarilla que denota la tendencia actual de la venta mensual de buses parece mantenerse en alza para los siguientes meses; y de acuerdo a lo reportado por Edwin Darteano, presidente de la Asociación Automotriz del Perú esto se mantendrá así. Según Darteano (2018) los estándares internacionales señalan que lo ideal es que un mercado renueve como mínimo el $10 \%$ de su parque automotor cada doce meses y que la antigüedad promedio no exceda los 10 . Por nuestro país circulan 2 millones 600 mil vehículos cuya edad promedio es de 13 (párr. 1).

Darteano (2018) agrega que los estudios demuestran que Lima necesita de 15,000 buses nuevos para tener un buen sistema de transporte, menos de la mitad de las 36 mil unidades, muchas de ellas viejas y pequeñas, que causan gran congestión (párr. 2).

A continuación, se presentan las cifras propuestas por la AAP en colaboración con la SUNAT para la venta de cada tipo de transporte pesado durante el 2017 y a inicios del 2018 que respaldan lo dicho por el presidente de la AAP. 


\section{Tabla 4-1}

Detalle tipo de vehículo vendido hasta abril del 2018

\begin{tabular}{|c|c|c|c|c|c|c|c|c|c|c|c|c|c|}
\hline AÑO & TIPO & ene & feb & mar. & abr. & may. & jun. & jul. & ago. & sep. & oct. & nov. & dic. \\
\hline 2017 & camiones & 827 & 782 & 802 & 731 & 931 & 826 & 648 & 947 & 908 & 789 & 684 & 864 \\
\hline 2017 & buses & 294 & 219 & 220 & 277 & 374 & 382 & 316 & 392 & 405 & 354 & 397 & 475 \\
\hline 2017 & tractos & 249 & 177 & 230 & 161 & 231 & 212 & 238 & 276 & 361 & 232 & 204 & 198 \\
\hline 2017 & V. pesados & 1370 & 1178 & 1252 & 1169 & 1536 & 1420 & 1202 & 1615 & 1674 & 1375 & 1285 & 1537 \\
\hline 2018 & camiones & 740 & 799 & 823 & 1052 & & & & & & & & \\
\hline 2018 & buses & 391 & 286 & 340 & 553 & & & & & & & & \\
\hline 2018 & tractos & 238 & 262 & 217 & 328 & & & & & & & & \\
\hline 2018 & V. pesados & 1369 & 1347 & 1380 & 1933 & & & & & & & & \\
\hline
\end{tabular}

Fuente: AAP (2018)

Elaboración propia

Ahora, centrándonos en el funcionamiento comercial de la empresa Industrias Carroceras Quispe, el primer punto de comparación para analizar indicadores comerciales será la venta de la empresa recogida directamente de los Estados de Resultados de la empresa desde el 2014, datos que se muestran a continuación.

\section{Tabla 4-2}

Venta neta de la empresa industrias carroceras quispe

\begin{tabular}{|c|c|c|c|}
\hline AÑ̃ & $\mathbf{2 0 1 4}$ & $\mathbf{2 0 1 5}$ & $\mathbf{2 0 1 6}$ \\
\hline Ventas Netas & $965,927.00$ & $1,345,709.00$ & $1,736,790.00$ \\
\hline \% de margen & $46.25 \%$ & $41.04 \%$ & $17.05 \%$ \\
\hline
\end{tabular}

Fuente Industrias Carroceras Quispe (2017)

Elaboración propia

Respecto a los indicadores de rendimiento y volumen, se observa que las ventas netas de la empresa han aumentado en 39\% entre el 2014-2015 y 29\% entre el 2015-2016, debido a que la empresa está siendo reconocida por el mercado por el buen servicio que ellos brindan. Sin embargo, su margen de contribución respecto a las ventas es muy bajo, a pesar del aumento de las ventas en el transcurso del tiempo. Esto se debe a que sus costos variables son demasiados altos.

\subsubsection{Identificación de problemas}

- Política de promoción

Como se explicó con Oanterioridad, los principales clientes de la empresa Industrias Carroceras Quispe corresponden a Allin Group, consorcio de transporte 
dueños de las unidades que operan el corredor morado en la ruta San Juan de Lurigancho-San Isidro. Otros pequeños clientes corresponden a dueños de microbuses para el transporte público pero que pertenece a intereses privados, la mayoría de estos clientes tienen tiempo trabajando las reparaciones de sus unidades con el señor Víctor Quispe, y se fían de la calidad del servicio y del bajo precio que la empresa ofrece. La fidelización de clientes es importante en el sector de reparaciones automotrices; sin embargo, uno de los principales problemas que encontramos en el área comercial es el hecho de que no se promociona el servicio ofrecido ni se busca expandir a otros clientes.

Según lo conversado con el gerente general Víctor Quispe, ellos no buscan a sus clientes, solo trabajan con sus clientes frecuentes y el aumento de su clientela es justificado por la calidad de servicio que brinda como fue mencionado anteriormente. Esto se podría considerar una gran desventaja para la empresa, ya que solo se sostiene en base a la calidad de su servicio para atraer clientes, mas no en la promoción (Quispe Accostupa, Contreras Huatuco, \& Bravo Lando, 2017). Como se observa en el \% de gasto de ventas recogido desde el año 2014, además de ser estos gastos variables, el control e importancia que hace la empresa para el desarrollo de sus relaciones comerciales podría no ser el adecuado.

\section{Tabla 4-3}

\section{Porcentaje del gasto de ventas}

\begin{tabular}{|cccc|}
\hline AÑNO & $\mathbf{2 0 1 4}$ & $\mathbf{2 0 1 5}$ & $\mathbf{2 0 1 6}$ \\
\hline$\%$ GASTOS DE VENTAS & $32.38 \%$ & $1.08 \%$ & $0.00 \%$ \\
\hline
\end{tabular}

Fuente Industrias Carroceras Quispe (2017)

Elaboración Propia

En conclusión, el principal problema comercial de la empresa es su margen de contribución con respecto a las ventas. Ya que es muy bajo con respecto a las ventas y va decayendo en los últimos 3 años, se podría esperar una baja en los clientes no fidelizados, que corresponden aproximadamente al $30 \%$ de las ventas mensuales según lo confirma el gerente Víctor Quispe.

- Política de distribución

Un segundo problema importante hallado en el diagnóstico comercial es la restricción que implica tener un punto de distribución del servicio en una zona de 
difícil acceso para buses de proporciones mayores. El taller de reparaciones ubicado en el límite del distrito de Ate y Santa Anita podría no ser el indicado para satisfacer las necesidades de su mercado objetivo, Lima Metropolitana. Para los clientes llevar a refaccionar la carrocería después de un siniestro resulta mucho más conveniente un local que sea de fácil acceso en caso tenga que ser llevado por una grúa de carga.

Un estudio elaborado por la AAP determinó la participación de marcas en el mercado de vehículos pesados en el Perú. Como se describe en el gráfico presentado a continuación, el mayor tipo de vehículos de transportes pesados corresponden a las marcas Mercedes Benz y Mitsubishi.

\section{Figure 4-1}

\section{Distribución de marcas en el mercado peruano}

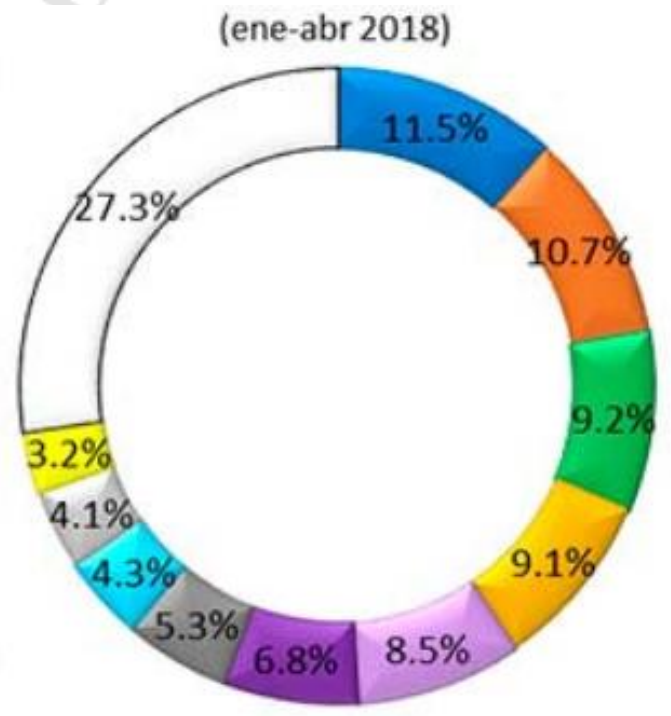

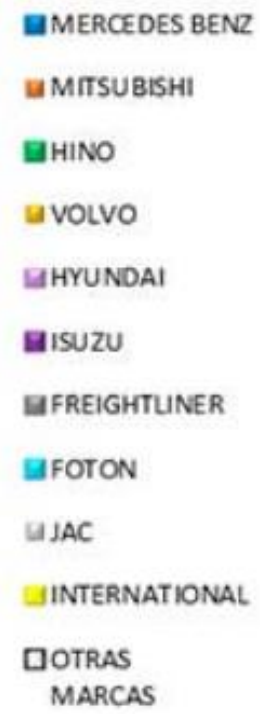

Fuente: AAP (2018)

Elaboración propia

Dado esto, y considerando que la mayoría de operadores viales operan con marcas determinadas, un aspecto importante a considerar en la política de distribución podría ser el de enfocarse en un taller especializado para las marcas de Mitsubishi y Mercedes Benz y situarlo cerca de las líneas donde operan los buses de esas marcas. 


\subsubsection{Determinación de fortalezas y debilidades}

- Debilidades

Las principales debilidades en la empresa se encuentran en el análisis de los métodos de gestión; esto es, la empresa Industria Carrocera Quispe tiene un registro de datos de sus principales clientes, en este se encuentra la frecuencia de solicitud de servicio y su nivel de ingresos, asimismo, cuenta con un registro en la logística de salida del servicio, en el cual el jefe de planta evalúa las condiciones del bus, si esta no cumple con todos los requerimientos de salida, es devuelto al área de producción y si los cumple, se le notifica al cliente que su producto ya está listo (Quispe Accostupa, Contreras Huatuco, \& Bravo Lando, 2017).

Lo que se observa también es que la empresa no lleva un registro del análisis de la evolución de ventas en el servicio a pesar de ser un servicio que se encuentra en la etapa de crecimiento. Además, la empresa no compara periódicamente los costos versus los precios; esto ocasiona que no se tenga un control sobre los costos, produciendo un margen de contribución muy bajo. Asimismo, la empresa cubre todos los gastos deducibles en los contratos con los clientes y eso genera mayores gastos variables, ya que no controlan de forma eficiente sus precios, la empresa busca la fidelidad de sus clientes y no un margen alto.

\section{- Fortalezas}

La política de la empresa es a nuestro criterio la mayor fortaleza que tiene en el proceso comercial. La empresa a pesar de estar en etapa de crecimiento supo posicionarse rápidamente en el mercado de reparaciones de carrocerías y el trato y calidad del servicio es reconocido por sus principales clientes. La fidelización de los clientes en la etapa de introducción fue aplicada muy eficazmente por el gerente general y eso le asegura un porcentaje de las ventas mensuales muy importante. 


\section{Capítulo V. Diagnóstico del Proceso Operativa}

\section{$5.1 \quad$ Ingeniería del servicio}

\subsubsection{Descripción técnica de los productos o servicios}

Los servicios ofrecidos por Industrias Carroceras Quispe se detallan a continuación:

\section{- Reparación o fabricación de carrocerías.}

Como se explica en las primeras páginas, el servicio de reparación de buses siniestrados se basa en la reconstrucción de estas carrocerías, o en la fabricación y reemplazo de las piezas dañadas. Generalmente, el refuerzo de las carrocerías se realiza con el remachado de fibra de vidrio.

En resumen, las ventajas de la utilización de los materiales compuestos de matriz polimérica en el sector del automóvil son éstos:

- Importante reducción de peso (Hasta el 50\%) y mejora de prestaciones

- Menores costes de fabricación

- Mayor resistencia a la abrasión y al desgaste (interesante en cojinetes y casquillos)

- Buen comportamiento ante cargas dinámicas (amortiguación)

- Absorción de impactos sin deformación apreciable

- Resistencia a agentes químicos (combustible, refrigerante, etc.)

- Resistencia a la corrosión

- Aislamiento térmico

- Funcionalidad estética

- Aerodinámica (facilidad de moldeo y conformación)

- Flexibilidad en el diseño

A modo de ejemplo, un laminado de resina epoxi reforzado con fibra de vidrio puede diseñarse con una relación de resistencia-peso nueve veces superior a una fabricada con acero. De esta manera es posible diseñar componentes con propiedades predecibles y controlables. 


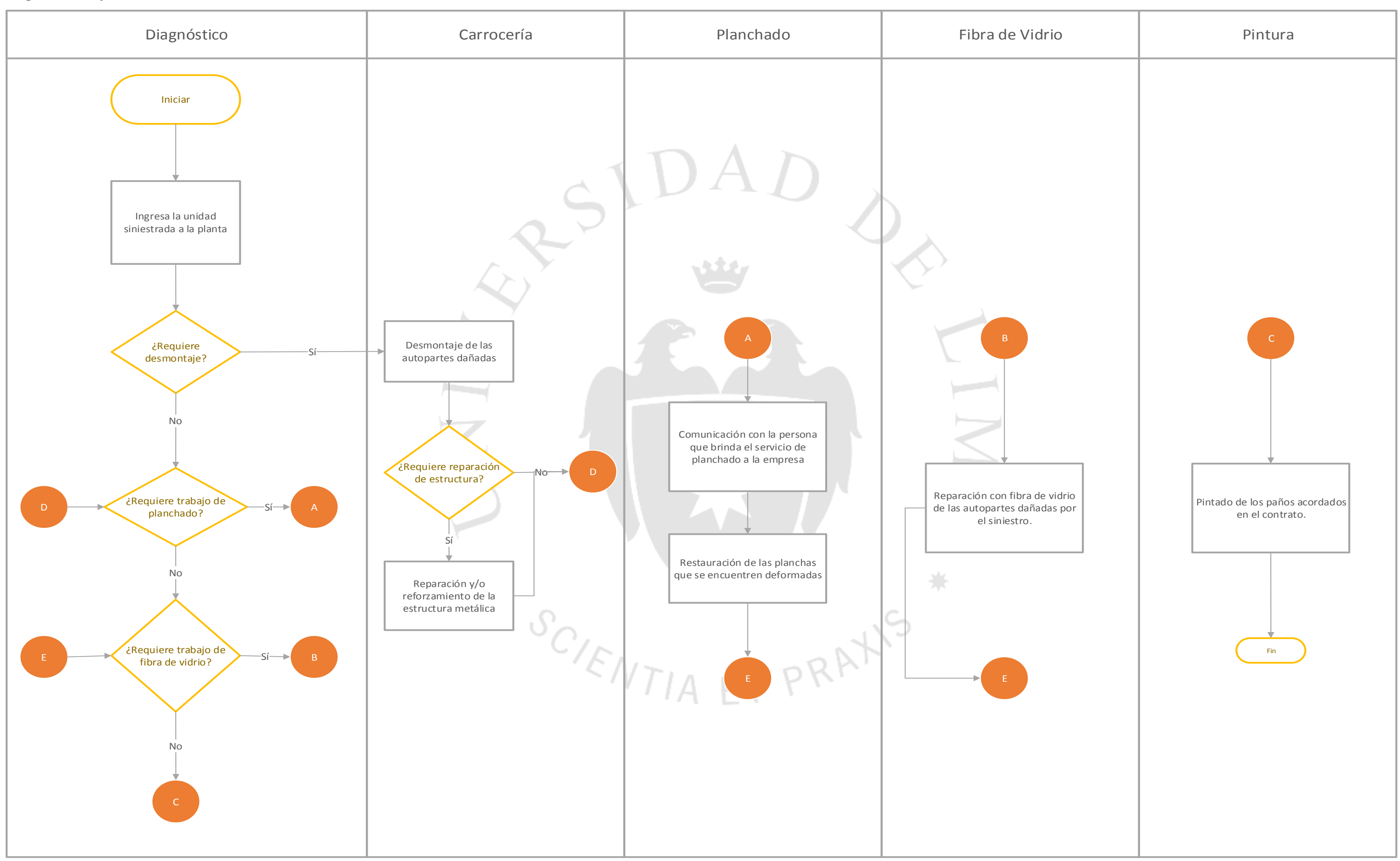

Elaboración propia 


\subsubsection{Descripción de las materias primas}

\section{- $\quad$ Fibra de vidrio}

Una de las aportaciones más importantes de la industria del automóvil ha sido el desarrollo de nuevos materiales para responder a las necesidades básicas de resistencia y de ligereza. De este modo, han aparecido paulatinamente materiales metálicos más ligeros y resistentes, materiales plásticos reforzados con fibra de vidrio, etc. Los materiales compuestos ocupan hoy en día un lugar preeminente tanto en la construcción de carrocerías como en el diseño de componentes mecánicos diversos. Los llamados composites aglutinan diferentes tipos de fibras de vidrio, carbono, aramida, etc., que son las encargadas de aportar las propiedades mecánicas; y una matriz, generalmente de naturaleza orgánica (resinas de poliéster, epoxy...), capaz de cohesionar las fibras, transmitir los esfuerzos y darle la configuración geométrica necesaria. La aplicación de los materiales compuestos de matriz polimérica en la industria del automóvil viene motivada sobre todo por su excelente relación resistencia-peso, que permite ahorros de energía significativos y que tiene evidentes ventajas desde el punto de vista medioambiental (Mata Cabrera, 2004).

\section{Figura 5-2}

Resumen de tipos de composites

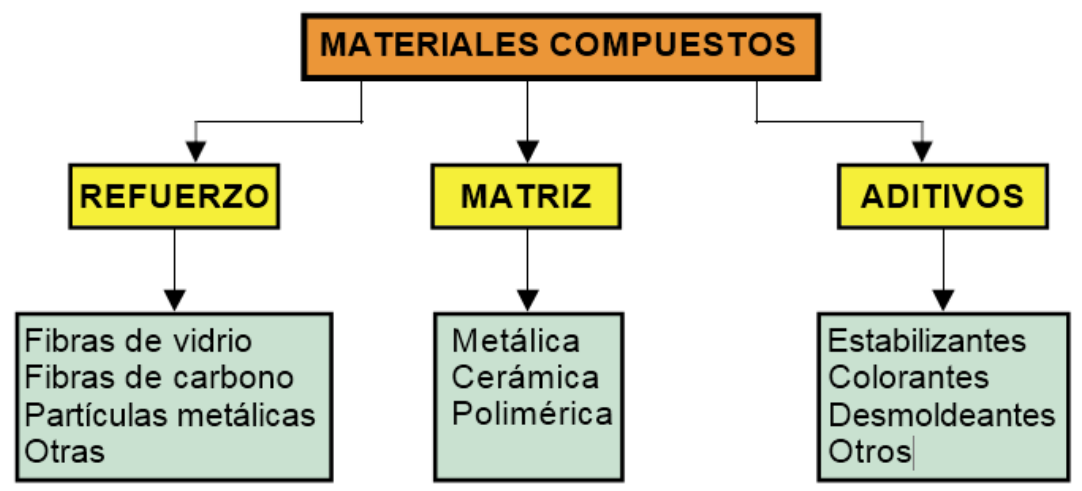

Fuente Polímeros de vidrio en la industria automotriz (2016)

Elaborado por Francisco Mata

Otros materiales usados en la industria de remachados son usados según la necesidad del cliente, al cual se le pregunta antes de realizar cualquier trabajo. El 
carbono, boro o la aramida son algunas de las materias primas empleadas por la empresa Industria Carrocera Quispe.

\section{Figura 5-3}

Descripción de los insumos

\begin{tabular}{|c|l|l|l|}
\hline VIDRIO & $\begin{array}{l}\text { Vuena relacion peso/prestaciones mecanicas } \\
\text { Facilidad de aplicacion }\end{array}$ & $\begin{array}{l}\text { Inconvenientes } \\
\text { Elevadas prestaciones mecanicas } \\
\text { especificas }\end{array}$ & $\begin{array}{l}\text { Autornocion } \\
\text { Construccion } \\
\text { Aeronautica }\end{array}$ \\
\hline CARBONO & $\begin{array}{l}\text { Excelente resistencia a la rotura en traccion } \\
\text { y compresion } \\
\text { Buena resistencia a la humedad }\end{array}$ & $\begin{array}{l}\text { Precio elevado } \\
\text { Escasa resistencia al choque }\end{array}$ & $\begin{array}{l}\text { Aeronautica } \\
\text { Autornoción } \\
\text { Biomecanica } \\
\text { Deporte }\end{array}$ \\
\hline ARAMIDA & $\begin{array}{l}\text { Buen comportamiento al choque } \\
\text { Buena resistencia a la humedad }\end{array}$ & Baja resistencia a la compresion & $\begin{array}{l}\text { Automocion } \\
\text { Construccion }\end{array}$ \\
\hline BORO & $\begin{array}{l}\text { Elasticidad elewada } \\
\text { Buen comportamiento al choque }\end{array}$ & Dificultad de utilizacion & Aerconautica militar \\
\hline
\end{tabular}

Fuente: Polímeros de vidrio en la industria automotriz (2016)

Elaboración propia

\subsubsection{Identificación de los principales proveedores}

Los principales proveedores de la empresa Industria Carrocera Quispe S.A.C. son Acces Bus, YOHERSA, TRADISA, Aluminio Center, etc.

- Acces Bus

El principal proveedor de accesorios importados que tiene la empresa, es un aliado estratégico, ya que, le ofrece sus productos a un precio menor que en el mercado.

\section{- YOHERSA}

Uno de los proveedores de fierros como tubos cuadrados, circulares y rectangulares.

- TRADISA

Es otro de los proveedores de fierros como planchas galvanizadas, ángulos, planchas galvanizadas, soldadura, etc.

- Aluminio Center

El principal proveedor de aluminios como planchas en bobina lisa o estriada, y también, planchas planas de diferentes espesores. 


\subsection{Análisis del proceso operativo}

\subsubsection{Análisis de resultados}

La información obtenida del área de operaciones es muy escasa, dado que, la empresa no ha implementado una política de documentación de procesos, materiales, mano de obra ni una gestión de indicadores, la cual, permitiría apoyarnos en una base sólida para el presente proyecto de investigación.

Es por lo cual, que se propone diversos indicadores que permitan mejorar el flujo de información entre las distintas áreas operativas, comerciales, etc; por ende, lograr los objetivos y metas que se tienen dentro de la organización. Dentro de los indicadores propuestos, se tomó muy en cuenta la incidencia que podría generar estos en el contorno global de la empresa.

El principal indicador que se propone es el "On Time In Full” (OTIF), ya que, al ser Industria Carrocera Quispe S.A.C. una empresa de servicios orientada mayormente al rubro de reparación de siniestros, es fundamental tener un indicador que mida la cantidad de servicios que se realizaron dentro del plazo estipulado en el contrato.

$$
\text { OTIF }=\frac{\text { Pedidos entregados a tiempo }}{\text { Total de pedidos }} \times 100 \%
$$

Además, se realizó un cuadro de entregas de los servicios durante los meses del año 2016, para poder apreciar el flujo de la cantidad de reparaciones de buses siniestrados realizada por la empresa.

En la siguiente tabla, se puede observar que los meses de trabajo no son constantes y que puede variar de algún suceso económico, político o legal, que pueda suceder en el estado peruano; por ejemplo, el año pasado, se tuvo picos en el servicio de pintado, ya que la normativa de la municipalidad de formalizar el transporte público en la ruta de Abancay-San Juan de Lurigancho, obligo a que muchas unidades sean refaccionadas y presenten los colores gris y morado que obliga la municipalidad y protransportes. 
Tabla 5-1

Relación de OTIF

\begin{tabular}{|c|c|c|c|}
\hline 2016 & OTIF & $\begin{array}{c}\text { Pedidos a } \\
\text { tiempo }\end{array}$ & $\begin{array}{c}\text { Total de } \\
\text { pedidos }\end{array}$ \\
\hline Enero & $60 \%$ & 6 & 10 \\
\hline Febrero & $75 \%$ & 6 & 7 \\
\hline Marzo & $67 \%$ & 8 & 12 \\
\hline Abril & $50 \%$ & 8 & 16 \\
\hline Mayo & $61 \%$ & 11 & 18 \\
\hline Junio & $63 \%$ & 10 & 16 \\
\hline Julio & $67 \%$ & 10 & 15 \\
\hline Agosto & $57 \%$ & 8 & 14 \\
\hline Setiembre & $63 \%$ & 10 & 16 \\
\hline Octubre & $67 \%$ & 12 & 18 \\
\hline Noviembre & $92 \%$ & 11 & 12 \\
\hline Diciembre & $70 \%$ & 7 & 10 \\
\hline
\end{tabular}

Fuente: Industria Carrocera Quispe S.A.C.

Elaborado por Quispe \& Contreras

Los resultados obtenidos de la tabla anterior, arrojan que el OTIF promedio anual de la empresa Industria Carrocera Quispe S.A.C. es de 66\%, lo cual, demuestra la ineficacia que tiene la empresa con relación al tiempo de entrega de los servicios pedidos.

El segundo indicador que se propuso es la utilidad bruta, la cual, pudo ser obtenida por el reporte de compras y ventas que entrega el contador de la empresa Industria Carrocera Quispe S.A.C.; además, se analizó la rentabilidad bruta para identificar si la empresa se encuentra manejando correctamente el costo de ventas. A continuación, se presentará la tabla con los valores indicados. 
Tabla 5-2

Datos de la rentabilidad bruta

\begin{tabular}{|c|c|c|c|c|}
\hline & Ventas & $\begin{array}{l}\text { Costo de } \\
\text { Ventas } \\
\end{array}$ & Utilidad Bruta & $\begin{array}{c}\text { Rentabilidad } \\
\text { Bruta } \\
\end{array}$ \\
\hline Enero & $171,156.38$ & 128179.01 & $42,977.37$ & $25.11 \%$ \\
\hline Febrero & $76,784.81$ & 64906.20 & $11,878.61$ & $15.47 \%$ \\
\hline Marzo & $102,538.54$ & 83312.56 & $19,225.98$ & $18.75 \%$ \\
\hline Abril & $145,148.39$ & 108234.25 & $36,914.14$ & $25.43 \%$ \\
\hline Mayo & $61,054.17$ & 48757.86 & $12,296.31$ & $20.14 \%$ \\
\hline Junio & $27,646.90$ & 20693.70 & $6,953.20$ & $25.15 \%$ \\
\hline Julio & $161,242.61$ & 130977.37 & $30,265.24$ & $18.77 \%$ \\
\hline Agosto & $91,749.10$ & 76647.20 & $15,101.90$ & $16.46 \%$ \\
\hline Setiembre & $166,924.70$ & 146678.40 & $20,246.30$ & $12.13 \%$ \\
\hline Octubre & $168,569.87$ & 146284.93 & $22,284.94$ & $13.22 \%$ \\
\hline Noviembre & $102,860.77$ & 86979.07 & $15,881.70$ & $15.44 \%$ \\
\hline Diciembre & $199,840.70$ & 159562.81 & $40,277.89$ & $20.16 \%$ \\
\hline
\end{tabular}

Fuente: Industria Carrocera Quispe S.A.C. (2017)

Elaboración propia

De los datos anteriores, se puede concluir que el costo de ventas de la empresa es muy elevado, dado que representa más del $70 \%$ del volumen de ventas, y esto afecta directamente al valor de rentabilidad bruta. Un valor de $18.85 \%$ como indicador de rentabilidad sobre ventas es muy bajo, dado que el valor meta que maneja la empresa es de $25 \%$; esto se da, gracias a una ineficiente política de compras y a un excesivo despilfarro de materiales por parte de los operarios.

El tercer indicador es el porcentaje de tiempo muerto que se encuentra dentro del área de operaciones, por lo cual, se realizó un estudio de tiempos para poder determinar el tiempo promedio que los operarios se encuentran inactivos. Para esto, la alta gerencia decidió que los procesos a evaluar son la carrocería, la fibra de vidrio, la pintura y la decoración. A continuación, se mostrará una tabla con valores estimados de los tiempos que se pudo determinar con el estudio en mención. 
Tabla 5-3

Cálculo del tiempo muerto

\begin{tabular}{|c|c|c|c|c|c|c|}
\hline Área & \# Operarios & Tiempo Nominal & $\begin{array}{l}\text { Tiempo muerto } \mathrm{x} \\
\text { operario } \\
\text { promedio al día }\end{array}$ & Tiempo real & $\begin{array}{l}\text { Eficiencia de } \\
\text { mano de obra }\end{array}$ & $\begin{array}{l}\text { Porcentaje del } \\
\text { tiempo muerto }\end{array}$ \\
\hline Carrocería & 8 & 3840 & 45 & 3480 & $90.63 \%$ & $9.38 \%$ \\
\hline Fibra de vidrio & 2 & 960 & 35 & 890 & $92.71 \%$ & $7.29 \%$ \\
\hline Pintura & 7 & 3360 & 40 & 3080 & $91.67 \%$ & $8.33 \%$ \\
\hline Decoración & 2 & 960 & 30 & 900 & $93.75 \%$ & $6.25 \%$ \\
\hline
\end{tabular}

Fuente: Industria Carrocera Quispe S.A.C.

Elaboración propia 
Con el cuadro anterior, se puede observar que los tiempos muertos, como la espera por materia prima, acercarse al almacén para realizar el pedido de alguna herramienta o equipo, la búsqueda innecesaria de herramientas por el desorden del área de trabajo o porque el operario nuevo está falto de conocimiento de las herramientas necesarias para realizar el trabajo.

Además, se pudo deducir que la pérdida económica de la empresa anualmente asciende al valor de S/. 42,195.00 soles, solo por el concepto de tiempo muerto de los trabajadores del área de operaciones.

Tabla 5-4

Perdida monetaria por tiempos muertos

\begin{tabular}{|c|c|c|c|}
\hline Área & Sueldo anual & $\begin{array}{c}\text { Porcentaje del } \\
\text { tiempo muerto }\end{array}$ & $\begin{array}{c}\text { Perdida } \\
\text { monetaria }\end{array}$ \\
\hline Carrocería & $222,240.00$ & $9.38 \%$ & $20,835.00$ \\
\hline Fibra de vidrio & $48,000.00$ & $7.29 \%$ & $3,500.00$ \\
\hline Pintura & $184,800.00$ & $8.33 \%$ & $15,400.00$ \\
\hline Decoración & $39,360.00$ & $6.25 \%$ & $2,460.00$ \\
\hline
\end{tabular}

Fuente: Industria Carrocera Quispe S.A.C. (2017)

Elaboración propia

Por lo cual, consideramos que este indicador representa el mayor problema en el área de operaciones, ya que, la perdida monetaria que presenta anualmente por este concepto es muy elevada. Por consiguiente, las propuestas de solución se basarán en solucionar este indicador y así, reducir los costos de producción tan elevados que tienen, asimismo, la rentabilidad neta se verá afectada con un incremento en su valor. 


\subsubsection{Identificación de problemas y causa raíz}

Figura 5-4

Diagrama de Thibaut de operaciones

\section{\%Tiempos muerto: $7.81 \%$}

Falta de política de renovación de equipos de producción

Falta de políticas de planificación de materiales

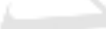
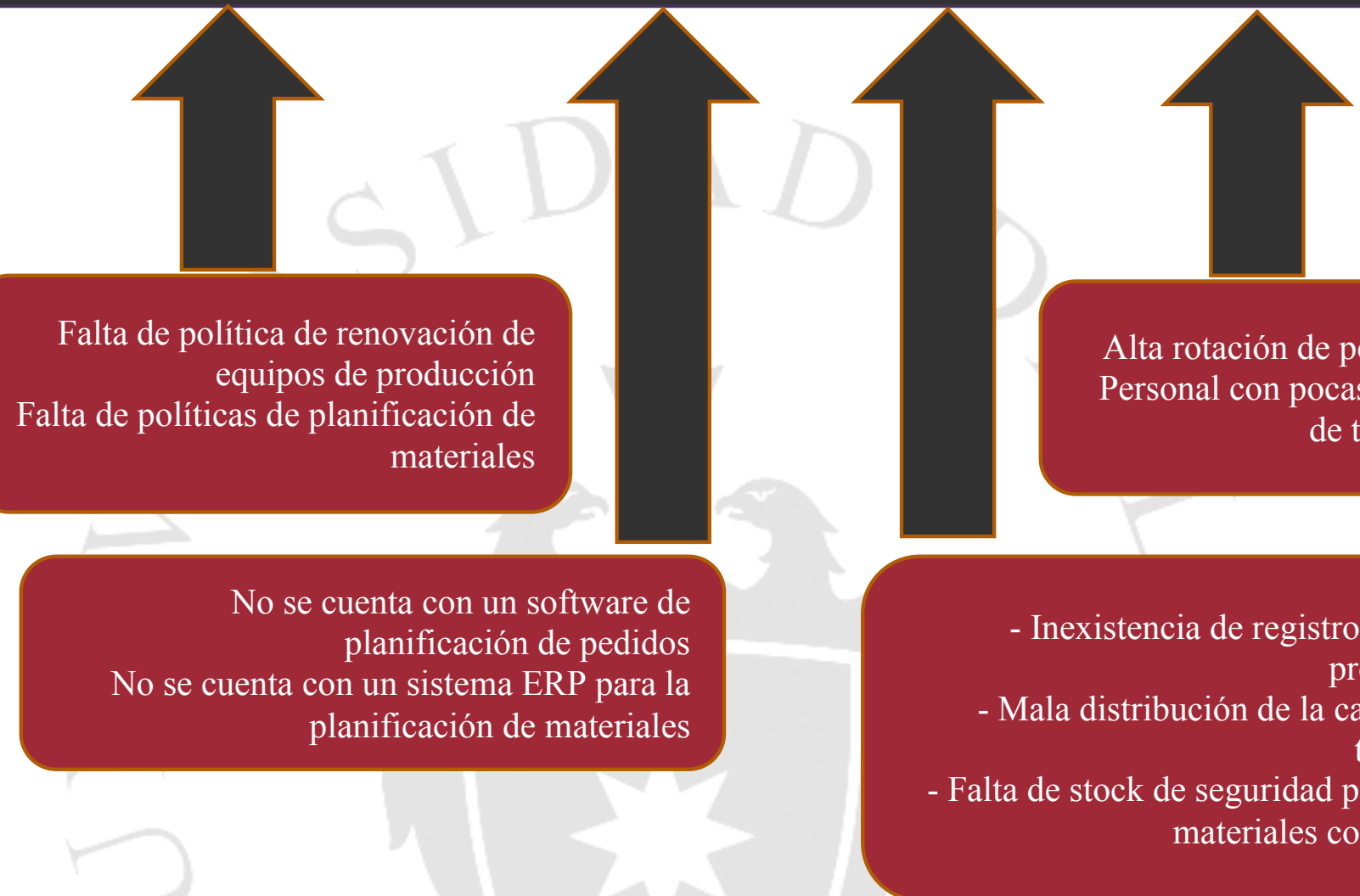

Alta rotación de personal

Personal con pocas ganas de trabajar

Fuente: Industria Carrocera Quispe S.A.C. (2017)

Elaboración Propia

Para determinar la causa raíz se pudo observar 4 criterios que permiten zonificar los principales problemas, como son los estudios de políticas, la revisión de medios y organización, el análisis de métodos de gestión y la relación con otros procesos. 
Figura 5-5

Diagrama de causa efecto del problema principal

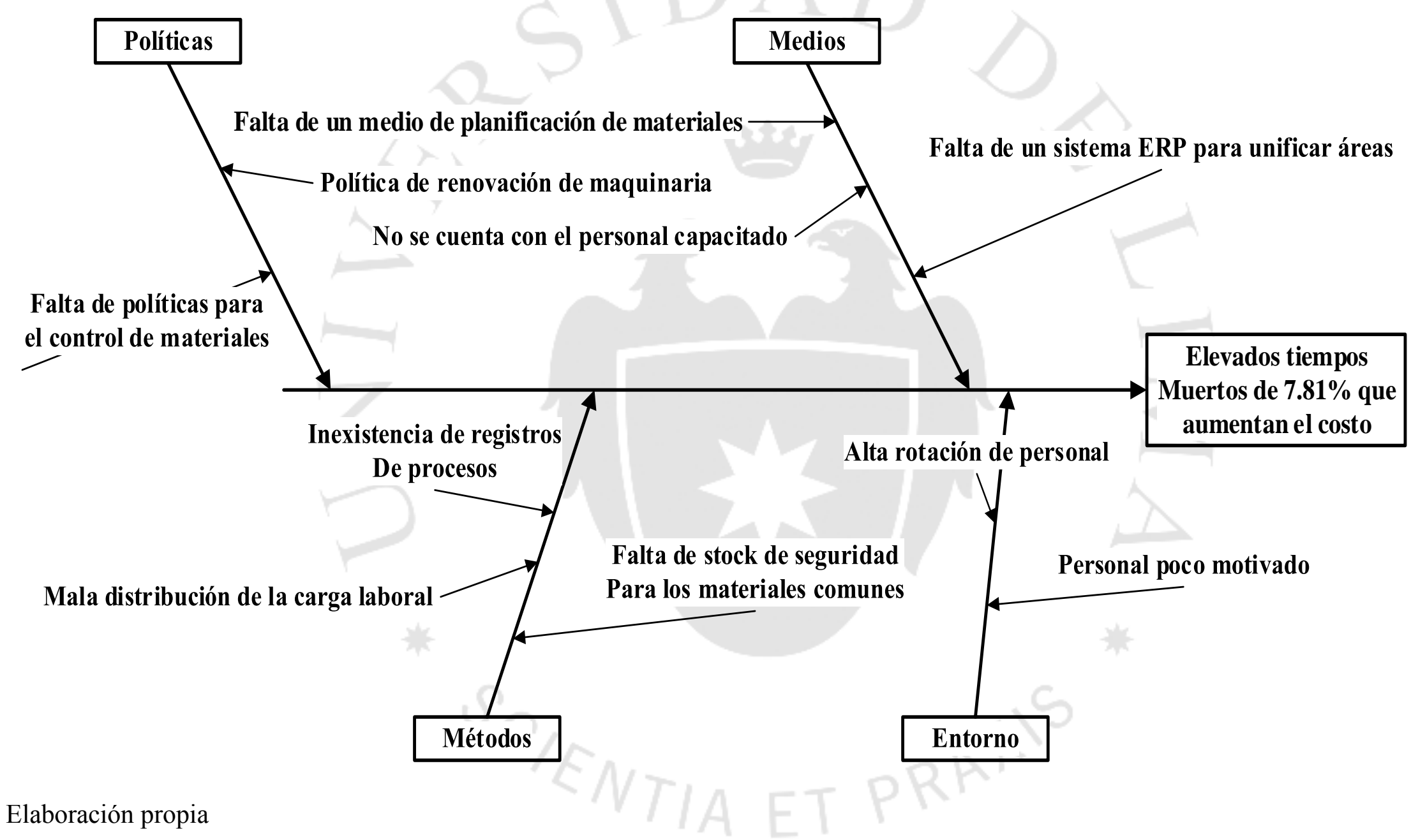




\subsubsection{Determinación de fortalezas y debilidades}

- Fortalezas

La principal fortaleza de la empresa en estudio, es que cuenta con mano de obra con experiencia en el rubro de los servicios que ofrecen, es por lo cual, que los clientes que tienen depositan su confianza para reparar sus unidades que han sufrido algún siniestro.

Sin embargo, la mala gestión de los activos está disminuyendo la credibilidad de los trabajos realizados, dado que, alargar el plazo pactado no genera una buena imagen ante los clientes.

- Debilidades

La principal debilidad del área de operaciones, es la falta de organización y planificación de los trabajos a realizar, es decir, los operarios tienen tiempos poco productivos, ya que la saturación de estos en un trabajo, disminuye el rendimiento personal.

Además, la falta de conocimientos técnicos de los operarios dificulta el flujo de información entre el área de planta y el área de compras, ya que, la inseguridad de los materiales comprados genera un retraso a la hora de entregar el servicio al cliente. 


\section{CONCLUSIONES}

- Se concluye que la empresa mantiene una alta fuerza de negociación con sus clientes, asimismo, la rivalidad que mantiene con sus competidores y la amenaza a nuevos entrantes también es una fuerza alta. Por otro lado, la fuerza de negociación que tienen con sus proveedores y la amenaza de productos sustitutos es baja.

- Se puede concluir que la estrategia genérica que maneja la empresa Industria carrocera Quispe S.A.C. es una segmentación por costos, dado que no abarca todo el mercado, sino solo el segmento de buses siniestrados.

- La empresa deberá mejorar el tiempo que demora en realizar el servicio, dado que, el indicador OTIF arrojó un valor de $66 \%$ el cual, se encuentra por debajo del valor ideal en la entrega de servicios, lo que podría causar problemas mayores dentro de la organización con sus clientes.

- La empresa no explota todo su potencial de ventas, debido a que, no invierte en realizar promoción de su marca y su método de difusión es muy precario.

- El impacto que genera el área de operaciones dentro de la organización es de gran impacto, sin embargo, la empresa no invierte en mejorar la calidad de su trabajo y de su mano de obra.

- Este impacto mencionado, se ve reflejado en el porcentaje de tiempo muerto que tiene un valor de $7.68 \%$, el cual impacta en la empresa con un valor de perdida de S/. 42,195.00 soles anualmente. 


\section{RECOMENDACIONES}

- Realizar encuestas y test continuamente a los operarios para asegurar la comprensión de las metodologías enseñadas y su fidelización con las nuevas prácticas.

- La empresa deberá implementar también mejoras en las áreas de ventas y compras para asegurar más eficiencia en los costos de repuestos y materia prima.

- Se deben aprovechar las oportunidades de captar más clientes en la gestión municipal, actualmente se vive un plan vial y la remodelación de la flota vehicular está dentro de los objetivos de la municipalidad de lima.

- La evaluación de los procesos y operaciones debe ser continua y planificada por la empresa para tener un buen desempeño laboral y económico. Además, se deben proponer y revisar las metas en las áreas de operaciones, es decir, ser actualizar y monitorear los indicadores designados durante el presente estudio.

- Se recomienda la especialización del área de operaciones para que mejore la imagen de la empresa en el aspecto de entregas de los servicios a sus clientes. 


\section{BIBLIOGRAFÍA}

Champagnat, U. (2002). Diagrama Causa-Efecto. Lima.

Foda-Dafo. (2018). foda-dafo.com. Obtenido de https://foda-dafo.com/5-fuerzas-deporter/

Ita, H. A. (2013). Mejora en los procesos de una empresa fabricante de maáquinas de automatización. Lima: Pontificie Universidad Católica del Perú.

Mata Cabrera, F. (2004). Utilización de composites de matriz polimérica en la fabricación de automóviles. Técnica Industrial.

MINAM. (2016). Clima. Perú.

MINTRA. (2011). Decreto Supremo $N^{\circ} 42-F$. Obtenido de Ministerio del Trabajo y Promoción del Empleo: http://www.mintra.gob.pe/contenidos/archivos/sst/DS_42_F.pdf

MINTRA. (2011). Ley $n^{\circ}$ 29783-Seguridad y Salud en el Trabajo. Obtenido de Ministerio del Trabajo:

http://www.mintra.gob.pe/LGT/ley_seguridad_salud_trabajo.pdf

Motor Pasion. (2015). Motor Pasion. Obtenido de https://www.motorpasion.com/coches-hibridos-alternativos/honda-crea-unanueva-tecnologia-para-combinar-el-aluminio-con-el-acero-en-sus-carrocerias

OSINERGMIN. (2016). Distribución de Electricidad.

PROTRANSPORTE. (2018). Portal de Protransporte. Obtenido de http://www.protransporte.gob.pe/index.php/protransporte/marco-legal 


\section{REFERENCIAS}

Asociación Peruana Automotriz. (2018). $2^{\circ}$ Boletin informativo 2018. Lima.

Braidot , N., Formento , H., \& Nicolini, J. (2003). Desarrollo de una metodología de diagnóstico para empresas PyMEs industriales y de servicios. Sarmiento, Argentina.

Cardenas Moza, M. E. (2016). MEJORA DEL PROCESO DE COMPRAS Y VENTAS DE REPUESTOS EN LA EMPRESA LABORATORIO DIESEL SENATINOS S.A. Lima.

Elsaber21. (Febrero de 2018). El saber 21. Obtenido de https://www.elsaber21.com/estrategia-de-las-5s-gestion-para-la-mejora-continua

INEI. (2016). Agua. Cuzco, Lima.

Info de Buses. (2014). Infodebuses.pe. Obtenido de https://www.infodebuses.com.pe/es/transportes/turismo-jaksa/

La República. (16 de Enero de 2017). larepublica.pe. Obtenido de https://larepublica.pe/sociedad/840198-presentan-77-modernos-buses-para-elcorredor-morado-de-sjl-video

MEF. (28 de Abril de 2018). Ministerio de Economía y Finanzas. Obtenido de https://www.mef.gob.pe/es/noticias/notas-de-prensa-y-comunicados?id=5671

Ministerio de transportes y comunicaciones. (2017). mtc.gob.pe. Obtenido de https://www.mtc.gob.pe/cnsv/documentos/muertosAccidenteTransito_20062017.pdf

Quispe Accostupa, C., Contreras Huatuco, Z., \& Bravo Lando, D. (2017). Diagnóstico empresarial de Industrias Carrocería Quispe. Lima.

Sacristán, F. R. (2005). Las 5 S orden y limpieza en el puesto de trabajo. FC Editorial.

SST soluciones. (13 de Junio de 2016). SST soluciones. Obtenido de https://sstsoluciones.com/2016/06/13/que-tipo-de-sistema-erp-conviene-a-laempresa/ 